\title{
A Survey on Energy Efficient Wireless Sensor Networks for Bicycle Performance Monitoring Application
}

\author{
Sadik Kamel Gharghan, Rosdiadee Nordin, and Mahamod Ismail \\ Department of Electrical, Electronic and System Engineering, Faculty of Engineering and Built Environments, \\ Universiti Kebangsaan Malaysia (UKM), 43600 Bangi, Selangor, Malaysia
}

Correspondence should be addressed to Sadik Kamel Gharghan; sadiq@siswa.ukm.edu.my

Received 14 May 2014; Revised 18 September 2014; Accepted 18 September 2014; Published 13 October 2014

Academic Editor: Laurent Francis

Copyright (C) 2014 Sadik Kamel Gharghan et al. This is an open access article distributed under the Creative Commons Attribution License, which permits unrestricted use, distribution, and reproduction in any medium, provided the original work is properly cited.

\begin{abstract}
Wireless sensor networks (WSNs) have greatly advanced in the past few decades and are now widely used, especially for remote monitoring; the list of potential uses seems endless. Three types of wireless sensor technologies (Bluetooth, ZigBee, and ANT) have been used to monitor the biomechanical and physiological activities of bicycles and cyclists, respectively. However, the wireless monitoring of these activities has faced some challenges. The aim of this paper is to highlight various methodologies for monitoring cycling to provide an effective and efficient way to overcome the various challenges and limitations of sports cycling using wireless sensor interfaces. Several design criteria were reviewed and compared with different solutions for the implementation of current WSN research, such as low power consumption, long distance communications, small size, and light weight. Conclusions were drawn after observing the example of an advanced and adaptive network technology (ANT) network highlighting reduced power consumption and prolonged battery life. The power saving achieved in the slave node was $88-95 \%$ compared to the similar ANT protocol used in the medical rehabilitation.
\end{abstract}

\section{Introduction}

Cycling requires a very high level of endurance supported by a high fitness level and a suitable training program and teamwork. Cycling is a highly competitive sport in which the margins between victory and defeat are typically measured in seconds or milliseconds. Statistical information can be used to further improve and refine team skills and cyclist training programs to increase competitiveness in international tournaments. Acquired data may be processed to produce athlete performance profiles. Comparisons of athlete profiles can be made occasionally to measure an athlete's progress and to monitor and supervise him or her so that a coach can correct any deficient parameters.

In this paper, different types of wireless sensor networks (WSNs), which are used to monitor the biomechanical and physiological parameters of the bicycle and cyclist, respectively, will be critically reviewed and compared. A comparison between these wireless sensor technologies will be carried out on the basis of several performance metrics related to physical activities involving both the bicycle and cyclist. Some biomechanical and physiological parameters relevant to the sensors are covered in terms of their specifications and applications to cycling monitoring, including heart rate, speed, cadence, and pedal power.

The purpose of this review is not to criticize but rather to formulate potential extensions to existing approaches and to understand future research challenges. In addition, a methodical review of the use of WSN in cycling applications is used to describe current WSN research implementations. The review compares wireless technologies and performance metrics from recent research. Also, an ANT network example was introduced to overcome the limitations of power consumption and battery life.

The contribution of this paper is to present a comprehensive overview of the many challenges that face the wireless sensor networks in the bicycle performance monitoring system. In addition, comparisons between different wireless technologies were done based on various performance metrics. We attempted to highlight several wireless 
sensor network technologies that are used in wireless sensor bicycle monitoring, thus providing a comprehensive, upto-date survey of wireless sensor networks research that is used in bicycle performance monitoring system. A new wireless sensor technology (i.e., ANT) that is used in bicycle performance monitoring was introduced, which aims to reduce the power consumption and prolong battery life of the bicycle performance monitoring system based on message rate reduction, as will be presented in Section 6. From the literature review, we found that ANT wireless technology offers significant potential in the area of energy efficient WSN transmissions. Our focus in this paper is on several wireless protocols which are connected to several bicyclerelated sensors. Furthermore, this survey provides a good number of latest references for those interested in the area of wireless sensor bicycle performance monitoring. Based on our limited knowledge, this review paper is the first paper that deals with the extensive survey of wireless sensors for bicycle performance monitoring, focusing on energy efficient WSN protocols.

The rest of the paper is structured as follows. Section 2 describes the problem statement of the cycling team. The comparisons of types of wireless technologies used to transfer data from the cyclists will be presented in Section 3. The common biomechanical and physiological parameters in the cycling sport will be introduced in Section 4 . Section 5 categorizes and describes previous work according to the type of wireless technology, highlighting the research methodology, advantages, and disadvantages of each research. In addition, a table of comparison for the research will be summarized. Furthermore, the biomechanical and physiological signals and sensors related to both bicycle and cyclist will be described in the same section. Section 6 will explain a proposed example of bicycle wireless sensor monitoring. Future works and a maturity evaluation will be introduced in Section 7. Finally, conclusions will be presented in Section 8 .

\section{Problem Statement and Challenges}

Before advances in sensor development technologies, a cycling training program once depended mainly on the conventional stopwatch [1] to measure the performance of athletes. This method is inaccurate and uninformative when used to measure the performance and capability of an athlete on the track. Furthermore, this method also lacks scientific support, as there is no evidence that training with a stopwatch can improve the competitive performance of an athlete. There are many challenges when attempting to implement wireless sensor devices and networks specifically in bicycle performance monitoring systems as follows.

(i) The monitored parameters of the bicycle must be real time and accurate, so that coaching staff can give instant feedback to improve the performance of cyclists.

(ii) The wireless sensor monitoring system must operate at low power consumption (i.e., the battery must last for at least five hours of training). (iii) There must be a flexible transmission range between the cyclist and coaching teams as it depends on the type of discipline, such as, track, road, or crosscountry.

(iv) Ideally, lightweight and small-size wireless sensors and display units (mounted on the bicycle) are desired, especially for a highly competitive professional tournament.

(v) The system should expand to include additional (new) measurement parameters, such as body temperature, left/right axis (gyro sensors), specific athlete power profiles, and stress level.

(vi) An efficient algorithm must be introduced to reduce the power consumption of the three main consumers of power in the WSN, namely the sensors, microcontroller, and transceiver.

\section{Wireless Technologies}

There are many wireless technology standards which have been adopted for bicycle monitoring systems. Two of the most commonly available wireless protocols are ZigBee [2] and Bluetooth [3]. There is also alternative wireless standard ANT, which is commonly used in sensor networks $[4,5]$. As is customary, wireless technology requirements such as transmitted power $(\mathrm{dBm})$, data rate $(\mathrm{kbps})$, the range of communications (m), power consumption (W), and weight (kg) differ among these standards. Practically, the power consumption, weight, and size must be as small as possible and the coverage area of the network must be as large as possible to improve the performance of the cyclist. For example, one worst-case scenario occurs when cyclists and coach are positioned too far apart.

Three wireless standards occupying the $2.4 \mathrm{GHz}$ ISM band used in cycling monitoring are Bluetooth, ZigBee [6], and ANT, where ANT is commonly used in commercial products. Bluetooth operates in the $2.4 \mathrm{GHz}$ ISM band, with a broadband speed 1 to $24 \mathrm{Mbps}$ depending on the Bluetooth version [7] and a communication range of approximately $1 \mathrm{~m} / 10 \mathrm{~m} / 100 \mathrm{~m}$ [8]. Moreover, Bluetooth is a "lighter" standard that is extremely ubiquitous (e.g., it is built into most mobile phones, PDAs, and laptops) and can easily be adapted to several other services or networks [9].

ZigBee is a wireless technology that operates in the $868 \mathrm{MHz}, 915 \mathrm{MHz}$, and $2.4 \mathrm{GHz}$ frequency bands [10]. ZigBee was designed mainly for low-power-consumption applications, with additional features such as low cost, low data rate (maximum of $250 \mathrm{Kbps}$ ), and long battery life. In many ZigBee applications, the wireless device participation or contribution is very limited; the device spends most of its time in sleep mode. As a result, ZigBee device batteries are capable of working for several years and do not need to be replaced [11]. ZigBee enables broad-based deployment of wireless networks with an approximate communication range of $100 \mathrm{~m}$. This allows it to work for years on small coin batteries for a host of control and monitoring applications, such as smart grid [12], patient monitoring [13], automation systems [14], control systems [15], and several other applications. 
TABLE 1: Comparison between wireless technologies used in bicycle monitoring.

\begin{tabular}{|c|c|c|c|}
\hline \multirow{2}{*}{ Parameters } & \multicolumn{3}{|c|}{ Wireless technology } \\
\hline & Bluetooth (IEEE802.15.1) & ZigBee/IEEE802.15.4 & ANT \\
\hline Frequency band(s) & $2.4 \mathrm{GHz}$ & $868 / 915 \mathrm{MHz}, 2.4 \mathrm{GHz}$ & $2.4 \mathrm{GHz}$ \\
\hline Data rate & $\begin{array}{c}1 \mathrm{Mbps}^{1}[104], 1.2 \mathrm{Mbps}^{2} \\
{[105]} \\
3 \mathrm{Mbps}^{3}[106], 24 \mathrm{Mbps}^{4} \\
{[105]}\end{array}$ & $\begin{array}{c}20 \mathrm{kbps}^{\mathrm{a}}, 40 \mathrm{kbps}^{\mathrm{b}}, \\
250 \mathrm{kbps}^{\mathrm{c}}[107]\end{array}$ & $1 \mathrm{Mbps}$ \\
\hline Output power & $\begin{array}{c}0 \mathrm{dBm}^{5}, 4 \mathrm{dBm}^{6} \\
20 \mathrm{dBm}^{7}[108]\end{array}$ & $(-25-0) \mathrm{dBm}$ & $0 \mathrm{dBm}$ \\
\hline $\begin{array}{l}\text { Transmission } \\
\text { range }\end{array}$ & $1 \mathrm{~m}^{5}, 10 \mathrm{~m}^{6}, 100 \mathrm{~m}^{7}[108]$ & $(10-100) \mathrm{m}$ & $30 \mathrm{~m}$ \\
\hline $\begin{array}{l}\text { Power } \\
\text { consumption }\end{array}$ & $(40-100) \mathrm{mW}$ & $1 \mathrm{~mW}$ & $0.183 \mathrm{~mW}$ \\
\hline $\begin{array}{l}\text { Battery life (coin } \\
\text { cell) }\end{array}$ & (1-7) days & (4-6) months & $3+$ years \\
\hline Latency & $<10 \mathrm{sec}$ & $(20-30) \mathrm{ms}$ & $\approx$ Zero \\
\hline Spreading type & FHSS & DSSS & $\begin{array}{c}\text { Adaptive } \\
\text { isochronous }\end{array}$ \\
\hline $\begin{array}{l}\text { Number of devices } \\
\text { in network }\end{array}$ & $\begin{array}{c}7 \text { (active)/255 (total) } \\
{[109]}\end{array}$ & 65535 & $2^{32}$ \\
\hline $\begin{array}{l}\text { Number of RF } \\
\text { channels }\end{array}$ & 79 & One $^{\mathrm{a}}, 10^{\mathrm{b}}, 16^{\mathrm{c}}[110]$ & 125 \\
\hline Complexity & High & Low & Low \\
\hline Network topology & $\begin{array}{l}\text { Ad-hoc, point to point, } \\
\text { star }\end{array}$ & $\begin{array}{l}\text { Ad-hoc peer-to-peer, } \\
\text { mesh, and star }\end{array}$ & $\begin{array}{c}\text { Broadcast ad } \\
\text { hoc peer to peer, } \\
\text { mesh, and star }\end{array}$ \\
\hline
\end{tabular}

The third type is ANT, an ultralow-power proprietary wireless technology that operates in the $2.4 \mathrm{GHz}$ spectrum [16]. It was set up in 2004 by sensor company Dynastream [17]. Typically, the ANT transceiver device is treated as a black box and should not require much design potential to implement; that is, it is considered an infrastructureless network. ANT has been designed to cater for sports [18], the medical field [19], and industry [20], especially for performance monitoring of cyclists' and athletes' fitness levels. The ANT transceivers have been built into equipment such as cycle power meters, cadence meters, speed monitors, distance meters, and heart-rate belts to form personal area networks (PANs) for performance monitoring of users. For example, these networks have measured the performance metrics of speed, heart rate, and weight. The three key areas of operation of ANT are as follows: (i) sports, (ii) wellness, and (iii) home health [18]. It may also be used for data transfer to a number of devices; in this paper, a sport cycling application will be considered.

The main differences between the three protocols used in bicycle monitoring are summarized in Table 1 [21-31]. ZigBee and Bluetooth protocols are based on an IEEE 802 standard while ANT is not based on this standard. Classic Bluetooth, ZigBee, and ANT use a low data rate. Broadly speaking, Bluetooth and ZigBee are designed for a wireless personal area network (WPAN) communication range of approximately $100 \mathrm{~m}$, while ANT is specified for a WPAN range of approximately $30 \mathrm{~m} \mathrm{[32].} \mathrm{Compared} \mathrm{to} \mathrm{Bluetooth,}$ the ZigBee protocol is typical for WSNs or control applications, which require low data rate, and low complexity [33]. In addition, Zigbee can support for a large number of nodes in the network (up to 65,535), easy removal or addition of nodes of the network, a powerful mesh network such that the failure of one node does not bring down the rest of the network, and low power requirements [34].

A direct comparison of ANT to ZigBee is appropriate. ZigBee's/IEEE 802.15.4 standard for the $2.4 \mathrm{GHz}$ ISM frequency band has an over-the-air data rate of $250 \mathrm{kbps}$ [ 35 , 36] compared to ANT's $1 \mathrm{Mbps}$ [37]. Therefore, ZigBee is required to transmit over-the-air for longer than ANT for a given volume of data. ANT has been designed to stay in an ultralow-power mode (i.e., a sleep mode) for long periods, rapid wake-up [38], rapidly transmit for $150 \mu \mathrm{s}$, and return to sleep mode. In terms of latency the Bluetooth has high latency less than 10 second, ZigBee $30 \mathrm{~ms}$ [27], and ANT approximately zero latency $[17,39]$. Latency is a very critical issue for cycling application because the cyclist parameters must be monitored in real time.

ZigBee and Bluetooth utilize direct sequence spread spectrum (DSSS) [40] and frequency-hopping spread spectrum (FHSS) [41] schemes, respectively, to ensure the safety of the wireless link, whereas ANT uses an adaptive isochronous [42] network technology to assure coexistence. 


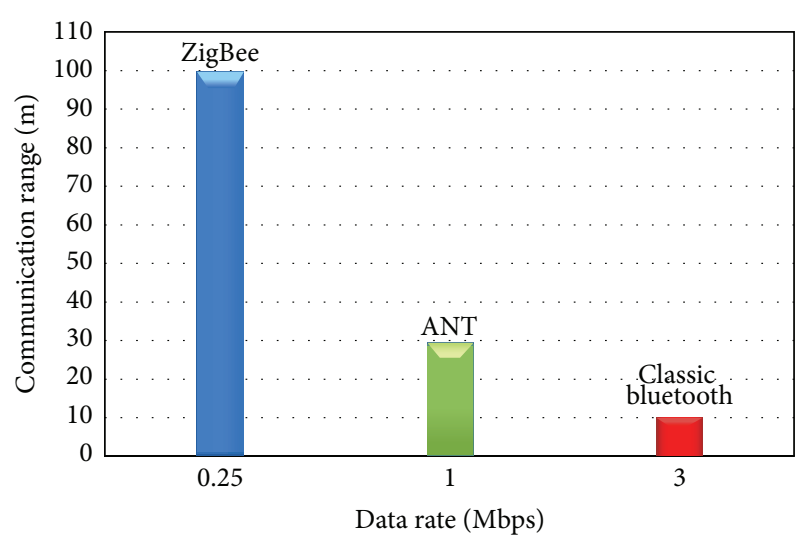

FIGURE 1: Data rates and communication ranges of several wireless sensor technologies.

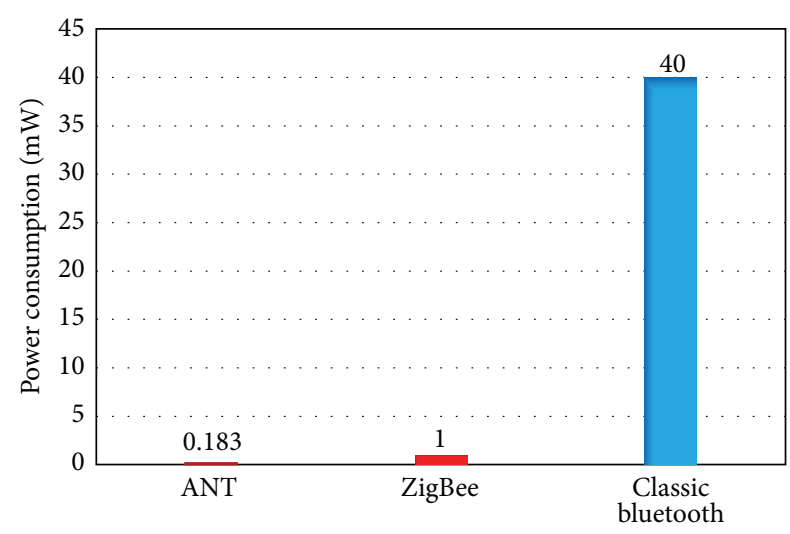

Figure 2: Power consumption of wireless sensor technologies.

Figure 1 shows a comparison of the data rates and communication ranges between wireless technologies used in wireless sensor bicycle monitoring, while Figure 2 shows the power consumption for these wireless technologies.

From the previous discussion, it is clear that the existing wireless standards, Bluetooth and ZigBee are unsuitable to address the wireless monitoring of sport cycling performance, on account of either power consumption or hardware complexity. In addition, latency is better for ANT compared to Bluetooth and ZigBee.

As a response to this topic, the sensor company Dynastream solved real problems in wireless sensor monitoring by introducing ANT wireless standard technology [43]. This wireless standard enjoys ultralow-power consumption [44] and small size and is therefore extremely suitable for WSN applications requiring long battery life, especially in sport and health monitoring.

\section{Biomechanical and Physiological Parameters in Cycling}

Most research works are concerned with four common bicycle parameters: (i) speed, (ii) heart rate, (iii) cadence, and (iv) power. These four parameters are key factors in improving the performance of cyclists, which are explained as follows.

4.1. Speed or Tire Rotation. The tire rotation or speed of the bicycle is the number of wheel rotations or revolutions per minute (RPM). Knowing the speed allows cyclists to avoid overtraining by regulating the training load [45] and it quantifies the external load [46]. The speed or tire rotation can be measured by using a magnetic sensor (reed switch) and a permanent magnet. The magnetic sensor is placed on the fork blade on the front wheel or on the chainstay of the rear wheel and the permanent magnet is fixed on one spoke on the front or rear wheel. The number of pulses generated by the sensor is directly proportional to the rotations of the rear or front wheel (RPM) and the ground speed of the bicycle $v_{b}$ can be calculated in kilometers per hour (KPH) or miles per hour $(\mathrm{MPH})$, based on the following equation:

$$
v_{b}=\mathrm{RPM} \cdot r \cdot\left(\frac{2 \pi}{60}\right)=\omega \cdot r,
$$

where $r$ is the wheel radius in meter and RPM is the wheel angular velocity and $(2 \pi / 60)$ is the unit transformation of revolution per minute into radians per second.

4.2. Heart Rate. The heart rate (HR) is the number of heart beats per minute. The heart rate monitor device is usually mounted on the athlete's body in the form of a belt around the chest that contains a pulsed wireless sensor. The HR device is able to measure and evaluate the physical health condition of the athlete. Knowing the heart rate is important to allow each cyclist to achieve his or her training plan as much as possible; the difference between the training heart rate and the reference value of each cyclist must be as small as possible [47]. The heart rate is also used to assess the physical stress or internal load that results from an external load [46]. The heart rate in cycling is interchangeable with the workload (watts) made by the cyclist; for example, the heart rate is 91 beats $/ \mathrm{min}$ when the workload is $25 \mathrm{~W}$, while it becomes 137 beats $/ \mathrm{min}$ when the workload is equal to $100 \mathrm{~W}$ [48].

4.3. Cadence. Cadence is the measure of the spinning speed of the pedals. The unit of measurement is revolutions per minute (RPM). The cycling power can be increased and the cyclist can be a productive part of the cycling team if the cyclist optimizes the cadence of the bicycle. Knowing the cadence allows cyclists to remain in a secure and an efficient range of revolutions per minute (RPM) to protect their knees [49], which is especially important over long distances. It is also possible to use the cadence to estimate the number of calories consumed during a bicycle trip. In addition, maintaining an ideal cadence (60-80) RPM helps a cyclist to consume calories efficiently. The cadence can be measured using a cadence sensor, which has two elements: a permanent magnet attached to the right crank arm of the bicycle and a magnetic sensor (reed switch) mounted on the chainstay. The pulses generated by the magnetic sensor are directly proportional to the crank rotations as measured in revolutions per minute (RPM). 
4.4. Pedal Power. Pedal power is the conversion of energy from the human source into motion through the use of the foot pedal and crank system of the bicycle. The pedal power is mainly of interest in the high-power range (more than $75 \mathrm{~W}$ ), which occurs during sports, rehabilitation activities, and exercise training. Knowing the cyclist power output allows the cyclist to optimize their performance, especially in competitions. Typically, the pedal power is used to quantify the external load. The pedal power can be measured by two methods. The first and most common method uses strain gauges attached to the right or left crank arm to measure the applied torque and at least one magnetic sensor that measures the RPM of the cadence. Therefore, the pedal power $\left(P_{c}\right)$ can be calculated by using the following formula [50-52]:

$$
P_{c}=T_{c} \cdot \mathrm{CAD} \cdot\left(\frac{2 \pi}{60}\right),
$$

where $T_{c}$ is the applied torque on the crank arm in N.m and CAD is the bicycle cadence or crank angular velocity in RPM.

The second method to measure pedal power is to calculate the sum of forces that face the cyclist during cycling. Many forces act on the cyclist and bicycle, but the major forces are air resistance force, rolling resistance force, gradient resistance force, and force due to the speed variables. Each force can be measured by using different sensors like temperature sensor, humidity sensor, pressure sensor, wind velocity sensor, and accelerometer sensor. The total pedal power $P_{\mathrm{DT}}$ can be calculated by multiplying the summation of these forces by the bicycle speed. Therefore, the total pedal power of the cyclist is modeled by [46, 53-55]

$$
P_{\mathrm{DT}}=\frac{\left[\left(F_{W} \cdot C F_{\mathrm{draft}}+F_{R}+F_{G}+F_{A}\right) \cdot v_{b}\right]}{c_{m}},
$$

where $F_{W}$ is the air resistance, $C F_{\text {draft }}$ is the effect of drafting, $F_{R}$ is the rolling resistance force, $F_{A}$ is the force due to speed variation, $F_{G}$ is the gradient resistance force, $v_{b}$ is the bicycle speed in $\mathrm{KPH}$, and $c_{m}$ is the mechanical efficiency factor.

\section{Previous Works}

Over the past decades, the issues of mobility, size [56], capability of processing (i.e., microprocessors or microcontrollers), flexible memory, and robust modes of transmission have been solved in wireless sensors due to the advancement in wireless sensor technology. Many new wireless standards provide a reliable and secure platform for a sensor network. Such wireless sensors support wearable [57], unobtrusive [58] equipment and also benefit from remote monitoring. This development benefits many practical applications including those in the realm of sports. In sports applications, a WSN allows the gathering and use of data in real time and it is also possible to compare data among athletes.

The transfer of data from an athlete or patient to a remote data processor or storage may now be performed remotely. The most common way to transfer the data is simply pointto-point, which means that one transmitter on the side of the athlete and one receiver on the monitoring side communicate based on frequency-modulated transmission [6].
In this section, several types of bicycle wireless sensor monitoring (BWSM) are critically reviewed. This review will be categorized based on the type of wireless technology or platform.

5.1. Systems Based on ZigBee Platforms. Muscle work, sweat level, and heart rate were monitored by Armstrong [6]. This study represents a beneficial introduction to how the ZigBee wireless technologies can be employed to improve the measurement process.

Advantage. Power consumption is reduced.

Disadvantage. Small coverage area limits communication due to limitations of the ZigBee standard.

The pedal power, speed, cadence, and heart rate data were transmitted separately for each cyclist to his computer via a ZigBee network in the work of Kuhn et al. [45]. They compared these measured parameters while developing the ABT system with commercial Schoberer Rad Messtechnik (SRM) power meters for twelve to thirty hours of bicycle riding. They found this system to be quite convincing.

Advantages. The system has low cost and lightweight overhead for cyclists and the transceiver unit can be used with multiple radio channels. Thus, many networks may be active at the same place in the same time period.

Disadvantages. The transmission range is $50 \mathrm{~m}$ in outdoor conditions and the notebook size is large. Another limiting factor is battery capacity, especially when the power plug is not available.

Le et al. [47] built an assisted bicycle trainer (ABT) with a predictive controller to measure the parameters of the bicycle and rider: speed (RPM), position in the group, and heart rate (bpm) of the cyclists. The collected data were transferred via a ZigBee network to a notebook computer for monitoring and supervision.

Advantage. The predictive controls of the ABT system were an effective way of training the cyclist group.

Disadvantages. The system did not consider other parameters such as power, velocity, cadence of the bicycle, and wind velocity, which were left for future work.

Walker et al. [59] monitored pulse heart rate (bpm), $\mathrm{SpO}_{2}$ (\%), skin temperature $\left({ }^{\circ} \mathrm{C}\right)$, ambient temperature $\left({ }^{\circ} \mathrm{C}\right)$, bicycle speed or wheel speed (KPH or MPH), and bicycle location based on a remote mobile monitoring system (RMMS). In addition, this system may be used to monitor vital events for the elderly.

Advantages. Low-power wireless sensors (ZigBee module), light weight, and real-time application (the time to transmit data from the sensor location to the remote device is approximately $10 \mathrm{~ms}$ ); monitoring can be performed by persons not admitted to the hospital or in a physician's office. This last 
advantage improves retrieval of the history of a person's status and allows a medical care center to service a huge number of people, reducing hospital visits and health care expenses, and enables the observer to recognize emergency situations quickly.

Disadvantage. The wireless sensor nodes (BioTE) have difficulty communicating when an obstacle blocks the line-ofsight between transmitter and receiver nodes.

Measurements of wheel spin rates (RPM), angular velocity (RPM) of the bicycle, steer angle, and the acceleration of three points on the frame were performed by Peterson et al. [60]. They were more ambitious than others in using a lowpower-consumption Xbee-pro wireless module interfaced to a microcontroller based on the Arduino platform to transmit the measured parameters to a monitoring system, based on GUI toolkits.

Advantages. The system created an accurate assessment of the lean via numerical integration and precise filtering of gyroscope signals, and the optical encoders are frictionless and have high reliability at low speeds with a fast dynamic response.

Disadvantages. The roll of the bicycle frame is difficult to directly measure, while the high precision of the optical methods is countered by both the weight and expense of the head unit. Optical methods can also be affected by road surface bending; reflectance and a larger battery size were required to supply the system.

Location estimation and radio reachability of the bicycle were determined by Hayashi et al. [61] using the ZigBee WSN. The bicycle's location can be estimated based on base stations, internet protocol gateways, and network management servers.

Advantages. Low power consumption, wide-area sensor network, monitoring over a long distance of $3.5 \mathrm{~km}$, remote reading, and remote control and bicycle management (including a temperature sensor, GPS sensor, luminance sensor, and acceleration sensor). The project found new services that are secure, eco-friendly, and safe.

Disadvantages. Large infrastructure, more components in the network, and the required line-of-sight between the transmission terminal and the base station.

Olieman et al. [62] measured vibrations of the bicycle produced from a combination of the wheels, speed, tire pressure, and road surface. Wireless inertial acceleration sensors (ProMove2) were used to measure the vibration of the bicycle in real time.

Advantages. Real-time measurements; the WSN nodes are connected to a computer by the fast gateway. GUI software is used to display the acquired data for further processing, while the receiver is designed to store the data every second, and automatic pausing is turned off.
Disadvantage. The experiment was partially unsuccessful because some of the frequencies were cancelled out more than others; for the best test and analysis parameters, more experiments are needed.

Marin-Perianu et al. [63] adopted a different approach from the others by focusing on determining the actual situation of the cyclist's lower limb segments in real-life and real-time conditions. A mobile WSN design was used to monitor lower-limb kinematics during cycling in real time. This design was based on ProMove (a low-power $2.4 \mathrm{GHz}$ wireless radio connected to a central node). The results of this system were compared with those of a camera system.

Advantages. The system has high accuracy with a simple wireless strap-on and the miniaturized sensing system can help cyclists outdoors during racing or training. Feedback is instant, which provides major benefits directly to users by providing them with comprehensive insight into body kinematics in real-life situations. The proposed system can be used for any motion sport, including swimming, rowing, skiing, and running.

Disadvantages. The system has limited resources, sensing accuracy, computational power, battery capacity, and robustness of wireless communication; there was error accumulation in the inertial measurement.

5.2. Systems Based on Bluetooth Platforms. Yang et al. [64] monitored the movements and breathing of a cyclist in addition to the road condition. The system consisted of clip sensors, accelerometer, microcontroller, Bluetooth module, and PDA.

Advantages. The system was low cost, durable, washable, comfortable, and wearable; the cyclist's health, safety conditions, and work were monitored and analyzed over the long term.

Disadvantages. The belt is large and relatively heavy on the cyclist compared to other belt sensors.

Casamassima et al. [65] developed a new platform to improve the rhythm and amplitude of Parkinson's disease patients by utilizing gait rehabilitation based on a wearable system eligible to produce real-time audio feedback via vocal messages to the patient in a comfortable and efficient way. The system composed of three basic elements: Android mobile phone based on Bluetooth wireless technology, inertial sensor nodes, and a microcontroller based on the ARM Cortex-M3.

Advantages. The system is mobile and unobtrusive. It is comfortable to wear and able to be carried by the patient without restriction and real life monitoring in both outdoors and indoors conditions.

Disadvantages. Power consumed is relatively high and battery lifetime of 6 hours. This means the battery must be recharged or replaced when used more than six hours. 
5.3. Systems Based on ANT Protocol. An ANT wireless sensor was used by Baca et al. [66] to monitor the biomechanical parameters of the bicycle: velocity $(\mathrm{KPH})$, cadence (RPM), distance $(\mathrm{Km})$, cyclist position, force $(\mathrm{N})$, inclination, and motion amplitude and physiological parameters of the athletes: heart rate (bpm) and heart rate variability. The measured parameters are transmitted to a remote location (coach) via a framework system which consists of ANT protocol, mobile phone, mobile network GPRS or UMTS, and internet networks. The coach gives feedback messages as advices to the athletes in the form of an alert pop-up message or ringtone alarm in order to improve their performance.

Advantages. The system enjoys low power consumption and low cost because of using the ANT protocol and mobile phones; in addition, the proposed approach used the possibility of infrastructure of the mobile and internet networks.

Disadvantage. The system used the default value message rate $(4 \mathrm{~Hz})$ for ANT devices in the framework. It was possible to make it less than $4 \mathrm{~Hz}$ (e.g., $1 \mathrm{~Hz}$ ), especially for physiological parameters where it does not change rapidly in order to reduce the power consumption and prolong battery lifetime of the sensor platforms.

The ANT transceiver was used by Johansson et al. [67] to analyze a Gait system for patients who need to rehabilitate gait or balance control after a stroke. They used ultralow-power wireless insole sensor biofeedback and the ANT transceiver interface with GSM/GPRS to send data to the home network via Bluetooth or to the Internet via GSM/GPRS. The gait system gives real-time biofeedback of squeeze allocation on the plantar surface during the stance phases of gait. The system helped to diagnose and treat these conditions and can also be used as a biofeedback system to monitor movement limits after joint surgery.

Advantages. The system showed good reliability and low power consumption and coexisted with both GSM/Wi-Fi and Bluetooth. The system has low latency and is based on an open-source mobile device. Therefore, the hardware is suitably available to build personal servers for a wireless body area network (WBAN) in a biofeedback gait-analyzing system.

Disadvantages. Higher power consumption at the high message rate (e.g., more than $4 \mathrm{~Hz}$ ) and a small amount of time jitter in the data sampling, as it is based on the TDMA access method.

Moreover, there are some researches such as $[46,68]$ were adopted Wi-Fi technology to form an ad hoc network for bicycle monitoring, but these researches are out of this study, on account of either power consumption or size of the system.

This narrative description of previous research is summarized in Table 2, which is arranged consecutively according to the type of wireless technology, with the addition of some other information, including hardware configuration and power efficiency.

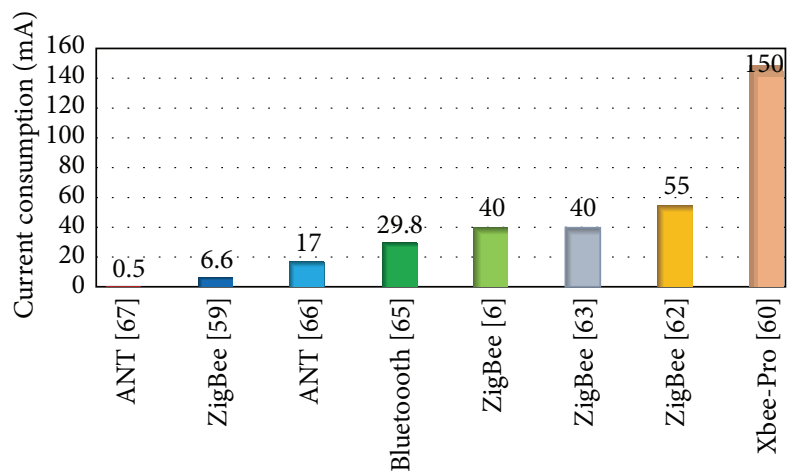

Wireless standard technology considered in previous researches

Figure 3: The current consumption of wireless sensor technology as listed in Table 2.

Through a review of previous researches which are summarized in Table 2, obviously, most of them supported the ZigBee wireless standard for bicycle monitoring. This protocol was most often selected as the wireless transmission technology because of its low cost [69], low power consumption $[70,71]$, higher network elasticity, a large number of nodes [72], greater coverage area, and secure networking [73]. Bluetooth is embedded in most portable mobile phones and computers [74] and has low cost, low EM interference [75], low-power applications [76], and low complexity [77], but it has appeared in few works considered in this study. ZigBee and Bluetooth are widely used in event monitoring because these two standards have low power consumption, which is a key feature of WSNs $[78,79]$.

ANT is the newest wireless standard technologies and is widely used in commercial cycling products such as SRM [80], PowerTap [81], Garmin Vector [82], and Pioneer [83]. However, there is still a lack of research literature related to bicycle monitoring that addresses this technology despite its use in health and rehabilitation monitoring as seen in Section 5.3. So, an example using this technology as an application for BWSM will be introduced in a later section.

Furthermore, a bar chart has been extracted from Table 2, as shown in Figure 3. This figure shows the current consumption comparison between wireless sensor technologies, which has been used in the previous research works. Figure 3 shows that the less power consumption was accomplished in research work in [67], which adopted ANT wireless standard technology. Some of research works aforementioned are related to the health (i.e., rehabilitation) applications, which based on Bluetooth and ANT wireless standard technologies are considered in this study. This is due to limited research works in sport cycling based on these technologies.

There are several performance metrics that have traditionally been chosen to quantitatively represent the achievements of the athlete and bicycle. In general, four of these performance metrics are most commonly used as demonstrated in the previous section. Measurement of the performance of these parameters depends on several sensing technologies, which are depicted in Table 3 , and the relevant location of the main sensors (key factor parameters) on a bicycle is shown 
TABLE 2: Comparison of previous works related to the bicycle wireless monitoring system.

\begin{tabular}{|c|c|c|c|c|c|}
\hline Authors & $\begin{array}{c}\text { Wireless } \\
\text { Technology/ } \\
\text { Platform } \\
\end{array}$ & Hardware configuration & $\begin{array}{l}\text { Biomechanical } \\
\text { parameters }\end{array}$ & $\begin{array}{l}\text { Physiological } \\
\text { parameters }\end{array}$ & $\begin{array}{c}\text { Power } \\
\text { consumed }\end{array}$ \\
\hline Armstrong [6] & ZigBee & ZigBee sensor network & $\mathrm{N} / \mathrm{A}$ & $\begin{array}{l}\text { (i) Muscle work } \\
\text { (ii) Heart rate (bpm) } \\
\text { (iii) Sweat rate }\end{array}$ & $40 \mathrm{~mA}$ \\
\hline Kuhn et al. [45] & ZigBee & $\begin{array}{l}\text { A stationary forwarder } \\
\text { node based on MicaZ } \\
\text { motes with modified } \\
\text { communication stack }\end{array}$ & $\begin{array}{l}\text { (i) Pedal power (W) } \\
\text { (ii) Cadence (RPM) } \\
\text { (iii) Speed (RPM) }\end{array}$ & Heart rate (bpm) & N/A \\
\hline Le et al. [47] & ZigBee & $\begin{array}{l}\text { ZigBee sensor network } \\
\text { configured as ad-hoc } \\
\text { network with Notebook }\end{array}$ & $\begin{array}{l}\text { (i) Power (W) } \\
\text { (ii) Velocity (RPM) } \\
\text { (iii) Cadence (RPM) }\end{array}$ & Heart rate (bpm) & N/A \\
\hline Walker et al. [59] & ZigBee & $\begin{array}{l}\text { BioTE Sensor with } \\
\text { MSP430, CC2420, GPS } \\
\text { RMMS, Cellular Network } \\
\text { and MySQL database }\end{array}$ & $\begin{array}{l}\text { (i) Bicycle speed or wheel } \\
\text { speed (RPM or MPH) } \\
\text { (ii) Bicycle location }\end{array}$ & $\begin{array}{l}\text { (i) Heart rate }(\mathrm{bpm}) \\
\text { (ii) } \mathrm{SpO}_{2}(\%) \\
\text { (iii) } \mathrm{Skin} \text { temp. }\left({ }^{\circ} \mathrm{C}\right) \\
\text { (iv) Ambient temp. }\left({ }^{\circ} \mathrm{C}\right)\end{array}$ & $6.6 \mathrm{~mA}$ \\
\hline Peterson et al. [60] & Xbee & $\begin{array}{l}\text { Xbee-PRO, } \mathrm{I}^{2} \mathrm{C}, \mathrm{ADC}, \\
\text { Arduino platform, and } \\
\text { AVR }\end{array}$ & $\begin{array}{l}\text { (i) Angular velocity } \\
\text { (rad/s) } \\
\text { (ii) Wheel spin rates } \\
\text { (rad/s) } \\
\text { (iii) Steer angle (degrees) } \\
\text { (iv) Acceleration of } \\
\text { three points fixed } \\
\text { to the frame (m/s }{ }^{2} \text { ) } \\
\text { (v) Roll angle (degree) }\end{array}$ & N/A & $150 \mathrm{~mA}$ \\
\hline Hayashi et al. [61] & ZigBee & $\begin{array}{l}\text { ZigBee, sensor, base } \\
\text { stations network, and } \\
\text { server with internet } \\
\text { protocol }\end{array}$ & $\begin{array}{l}\text { (i) Location estimation } \\
\text { (ii) Radio reachability }\end{array}$ & $\mathrm{N} / \mathrm{A}$ & N/A \\
\hline Olieman et al. [62] & ZigBee & $\begin{array}{l}\text { Inertial sensors based on } \\
\text { ProMove } 2 \text { and GPS }\end{array}$ & Vibration of the bicycle & $\mathrm{N} / \mathrm{A}$ & $55 \mathrm{~mA}$ \\
\hline $\begin{array}{l}\text { Marin-Perianu et } \\
\text { al. [63] }\end{array}$ & ZigBee & $\begin{array}{l}\text { WSN platform based on } \\
\text { ProMove }\end{array}$ & $\mathrm{N} / \mathrm{A}$ & $\begin{array}{l}\text { (i) Knee angle (degree) } \\
\text { (ii) Ankle angle (degree) }\end{array}$ & $40 \mathrm{~mA}$ \\
\hline Yang et al. [64] & Bluetooth & $\begin{array}{l}\text { Bluetooth, PDA, eight clip } \\
\text { sensors, MSP430, and } \\
\text { GPS }\end{array}$ & $\begin{array}{l}\text { (i) Velocity }(\mathrm{KPH}) \\
\text { (ii) Step counts } \\
\text { accumulated } \\
\text { (iii) Distance }(\mathrm{Km}) \\
\text { (iv) Road conditions }\end{array}$ & $\begin{array}{l}\text { (i) Amplitude of breathing } \\
\text { (ii) Rate of breathing } \\
\text { (iii) Posture } \\
\text { determination (sitting, } \\
\text { standing, walking, and } \\
\text { cycling) }\end{array}$ & N/A \\
\hline $\begin{array}{l}\text { Casamassima et al. } \\
{[65]}\end{array}$ & Bluetooth & $\begin{array}{l}\text { Android mobile phone } \\
\text { based on Bluetooth, } \\
\text { microcontroller based on } \\
\text { ARM Cortex-M3, and } \\
\text { accelerometer, gyroscope } \\
\text { and magnetometer } \\
\text { sensors }\end{array}$ & N/A & $\begin{array}{l}\text { (i) Steps per minute } \\
\text { (ii) Step length } \\
\text { (iii) Gait speed } \\
\text { (iv) Gait asymmetry } \\
\text { (v) Trunk flexion } \\
\text { (vi) Clearance }\end{array}$ & $29.8 \mathrm{~mA}$ \\
\hline Baca et al. [66] & ANT & $\begin{array}{l}\text { ANT (nRF24AP2) } \\
\text { protocol, Mobile phone, } \\
\text { mobile network } \\
\text { GPRS/UMTS, and } \\
\text { internet networks }\end{array}$ & $\begin{array}{l}\text { (i) Velocity }(\mathrm{KPH}) \\
\text { (ii) Cadence }(\mathrm{RPM}) \\
\text { (iii) Distance }(\mathrm{Km}) \\
\text { (iv) Bicycle position } \\
\text { (v) Inclination } \\
\text { (vi) Force (N) } \\
\text { (vii) Motion amplitude }\end{array}$ & $\begin{array}{l}\text { (i) Heart rate (bpm) } \\
\text { (ii) Heart rate variability }\end{array}$ & $17 \mathrm{~mA}$ \\
\hline $\begin{array}{l}\text { Johansson et al. } \\
\text { [67] }\end{array}$ & ANT & $\begin{array}{l}\text { ANT network based on } \\
\text { smart mobile phone, } \\
\text { sole-integrated gait } \\
\text { sensors, ATmega88, and } \\
\text { ARM cortex }\end{array}$ & $\begin{array}{l}\text { Pressure distribution on } \\
\text { the patient's shoes }\end{array}$ & $\begin{array}{l}\text { Balance control for } \\
\text { post-stroke patients }\end{array}$ & $500 \mu \mathrm{A}$ \\
\hline
\end{tabular}


TABLE 3: Biomechanical and physiological sensors related to the athlete and bicycle.

\begin{tabular}{|c|c|c|}
\hline $\begin{array}{l}\text { Biomechanical and } \\
\text { physiological signal } \\
\text { type }\end{array}$ & Sensor type & Description of the measured data \\
\hline Heart rate $[111,112]$ & Pulse belt sensor & $\begin{array}{l}\text { Measurement of the heart rate in } \\
\text { number of beats per minute. }\end{array}$ \\
\hline Speed [66] & Magnetic & $\begin{array}{l}\text { Calculation of the number of wheel } \\
\text { rotations in revolutions per minute } \\
(\mathrm{RPM}) \text { or linear speed in KPH. }\end{array}$ \\
\hline Cadence [66] & Magnetic & $\begin{array}{l}\text { Calculation of the number of crank } \\
\text { arm rotations in revolutions per } \\
\text { minute (RPM). }\end{array}$ \\
\hline Power [113-115] & Strain gauge & $\begin{array}{l}\text { Measurement of the applied torque on } \\
\text { the crank arm (N.m). }\end{array}$ \\
\hline Bicycle location [61] & GPS & $\begin{array}{l}\text { Determination of the bicycle's location } \\
\text { on the road. }\end{array}$ \\
\hline $\begin{array}{l}\text { Skin temperature } \\
{[116]}\end{array}$ & $\begin{array}{l}\text { Integrated } \\
\text { circuit LM35 }\end{array}$ & $\begin{array}{l}\text { Measurement of the athlete's } \\
\text { temperature }\left({ }^{\circ} \mathrm{C}\right) \text {. }\end{array}$ \\
\hline $\begin{array}{l}\text { Electrocardiogram } \\
(\mathrm{ECG})[117,118]\end{array}$ & Chest electrodes & $\begin{array}{l}\text { Measurement of the electrical heart } \\
\text { activity during cycling and } \\
\text { stair-climbing. }\end{array}$ \\
\hline $\begin{array}{l}\text { Oxygen saturation } \\
\left(\mathrm{SPO}_{2}\right)[119]\end{array}$ & Pulse oximeter & $\begin{array}{l}\text { Measurement the percentage (\%) of } \\
\text { the oxygen concentration in the } \\
\text { cyclist's blood. }\end{array}$ \\
\hline $\begin{array}{l}\text { Rate of breathing } \\
{[120]}\end{array}$ & $\begin{array}{l}\text { Respiration } \\
\text { sensor }\end{array}$ & $\begin{array}{l}\text { Measurement of the rate of breathing } \\
\text { (inspiration and expiration time) of } \\
\text { the cyclist. }\end{array}$ \\
\hline $\begin{array}{l}\text { Ankle and knee joint } \\
\text { angles [63] }\end{array}$ & Roll angle & $\begin{array}{l}\text { Monitoring of the ankle and knee } \\
\text { joints in order to control the power } \\
\text { transmitted to the pedals. }\end{array}$ \\
\hline $\begin{array}{l}\text { Ambient temperature } \\
{[121]}\end{array}$ & NFC thermistor & $\begin{array}{l}\text { Measurement of the ambient air } \\
\text { temperature }\left({ }^{\circ} \mathrm{C}\right) \text {. }\end{array}$ \\
\hline Bicycle position [122] & $\begin{array}{l}\text { GPS or bicycle } \\
\text { ID in wireless } \\
\text { sensor network }\end{array}$ & $\begin{array}{l}\text { Determination of the bicycle's position } \\
\text { in the group. }\end{array}$ \\
\hline $\begin{array}{l}\text { Route of the road } \\
{[123]}\end{array}$ & GPS & $\begin{array}{l}\text { Monitoring of the road in order to } \\
\text { avoid risks. }\end{array}$ \\
\hline Road conditions [64] & $\begin{array}{l}\text { Triaxial } \\
\text { accelerometer }\end{array}$ & $\begin{array}{l}\text { Measurement of triaxial acceleration } \\
\text { to give the safety conditions. }\end{array}$ \\
\hline Acceleration [123] & Tilt sensor & $\begin{array}{l}\text { Measurement of } \mathrm{X} \text { and } \mathrm{Y} \text { accelerations } \\
\text { of bicycle. }\end{array}$ \\
\hline Distance [124] & $\begin{array}{l}\text { Speed } \\
\text { multiplied by } \\
\text { time period }\end{array}$ & $\begin{array}{l}\text { Measurement of the distance travelled } \\
\text { by the bicycle. }\end{array}$ \\
\hline Steer angle $[60]$ & Potentiometers & $\begin{array}{l}\text { Measurement of the angular } \\
\text { displacement of the bicycle fork. }\end{array}$ \\
\hline Vibration [62] & $\begin{array}{l}\text { Inertial } \\
\text { acceleration }\end{array}$ & $\begin{array}{l}\text { Measure the vibration of bicycle in } \\
\text { seat, wheel axle, and front and rear } \\
\text { wheel. }\end{array}$ \\
\hline
\end{tabular}

in Figure 4. These sensors may be incorporated as part of a bicycle monitoring system, along with their corresponding measured biomechanical and physiological signals. The measurement of these signals and their subsequent processing for extracting some features is conducive to data collection of biomechanical and physiological parameters in real time, allowing an overall evaluation of the athlete and bicycle to be obtained at any time.

\section{Example of the Proposed BWSM}

In this section, a proposed example of BWSM based on ANT wireless standard technology will be highlighted. The ANT protocol operates in the $2.4 \mathrm{GHz}$ ISM band with 125 channels of width equal to $1 \mathrm{MHz}$ and a baud rate of up to $1 \mathrm{Mbps}$ [22]. In order to establish a connection between ANT devices or modules, the channel configuration must be common for 


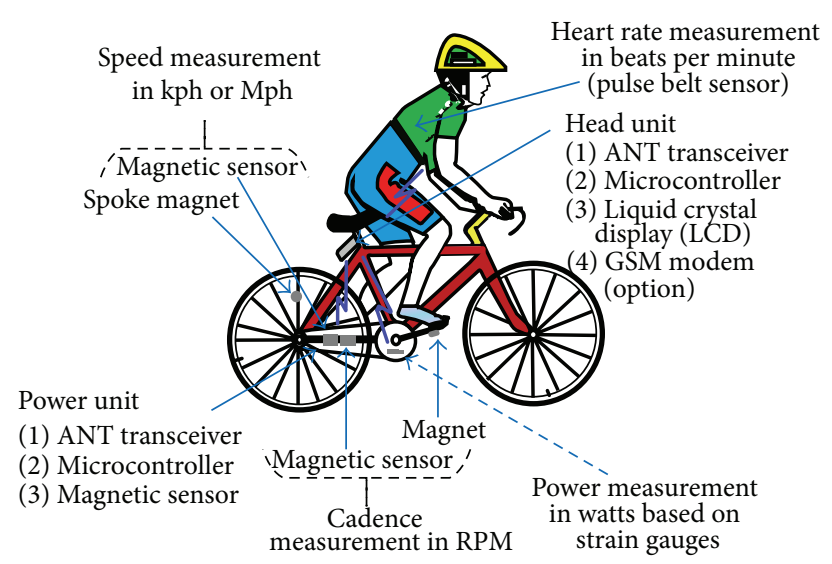

FIgURE 4: An overview of relevant wireless sensors and networks related to a bicycle and cyclist monitoring system.

these devices. There are several pieces of information related to the operating parameters of the channel that should be known for the ANT module in the network, which are [84] as follows.

(i) Network keys and network number ensure confidentiality and authorization access.

(ii) Radio frequency (RF): the radio frequency is 125 unique RF channels varying between " 0 to 124 ," representing the offset from $2.4 \mathrm{GHz}$ in $1 \mathrm{MHz}$ increments and can be calculated by the following formula:

$\mathrm{RF}$ freq. value $=\frac{\text { Desired RF freq. }(\mathrm{MHz})-2,400 \mathrm{MHz}}{1 \mathrm{MHz}}$.

The frequency value must be set the same for both the master and the slave nodes when the connection is created. For example, if the desired RF frequency is $2,466 \mathrm{MHz}$ (default RF frequency), it represents the $66 \mathrm{RF}$ frequency value.

(iii) Channel ID: in order for the ANT channel to be established, the host must specify its channel ID (whether it is master or slave).

(iv) Channel type: this specifies the type of communication (unidirectional adopted in this experiment) that will occur in the channel.

(v) Data types: there are four forms of data corroborated by ANT, namely, acknowledged, broadcast, burst, and advanced burst, each of which is transmitted in 8-byte packets over the desired RF channel.

(vi) Channel period: this represents the time interval between two successive data transmissions with broadcast data type. The channel message rate varies between 0.5 and $200 \mathrm{~Hz}$ and the default value is equal to $4 \mathrm{~Hz}$. The channel period is a 16-bit field with its value determined by the following expression:

$$
\text { Channel Period value }=\frac{32,768}{\text { Message Rate }(\mathrm{Hz})},
$$

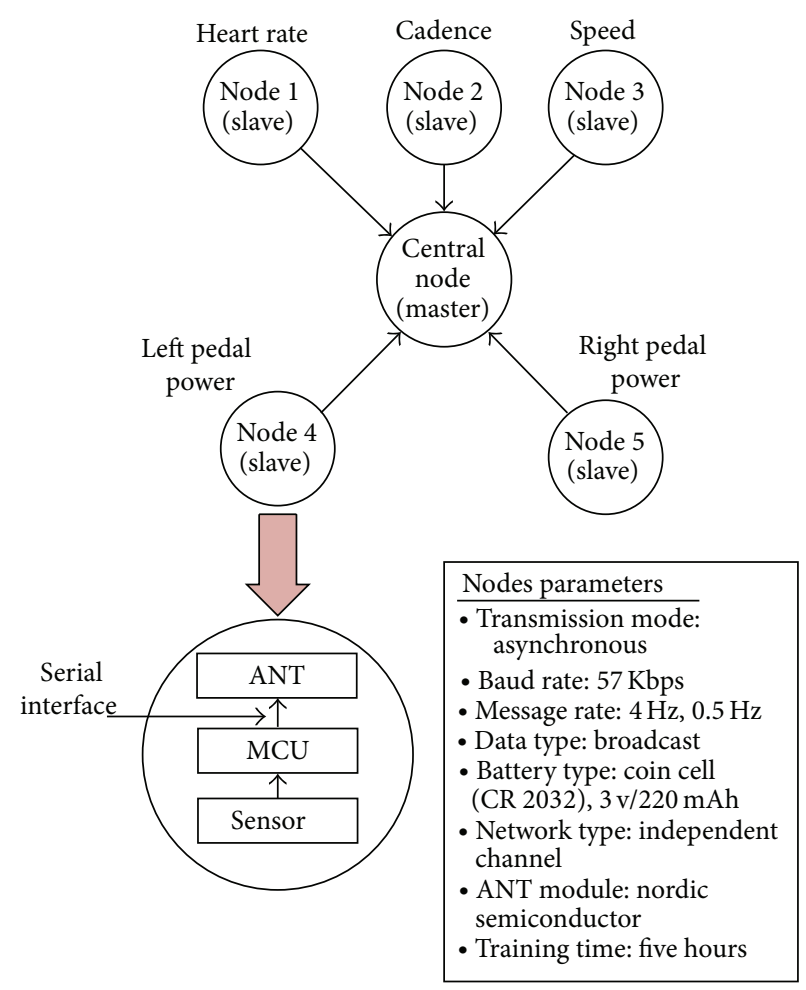

FIgURE 5: Example ANT network for bicycle wireless sensor.

where 32,768 represents an external clock source of the ANT module.

In the example of BWSM shown in Figure 5, six nodes form a simple independent channel network, five of them being slave nodes. Each node consists of a sensor, microcontroller, and ANT module. One node is the master node (central node) which consists of a microcontroller, ANT module and liquid crystal display (LCD). The slave nodes $(1,2,3,4$, and 5) log data from relevant sensors of heart rate, cadence, speed, and left and right pedal power, respectively. The collected data of biomechanical and physiological parameters from multiple slave nodes will be broadcasted to the master node. The master node receives and analyses this data, which later on will be displayed on the LCD to be viewed by the cyclist. The slave nodes only establish one channel and can therefore be executed using a single channel ANT module, whereas a master node requires a five-receivedchannels ANT module.

The power consumption and battery life of master and slave nodes were estimated based on the Power Estimator Tool [85], and the Nordic Semiconductor nRF24AP2-8CH ANT module [86] was selected. The power consumption and battery life were estimated for two cases; in the first case, default values were used, while in the second case the message rate was changed.

First Case. By default, a broadcast (i.e., unidirectional) data packet will be sent by slave nodes and received by a master node in every time slot at the $4 \mathrm{~Hz}$ message rate; this message rate is chosen to provide more easily discoverable networks 


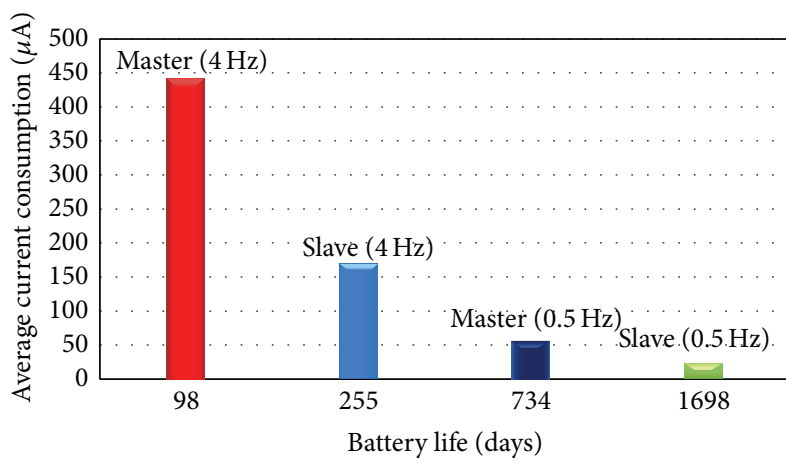

FIGURE 6: Current consumption and battery life for master and slave nodes.

with good latency and power consumption characteristics [84]. The baud rate at which the microcontroller can provide the data to ANT is set to $57 \mathrm{Kbps}$ in order to achieve maximum throughput [87]; besides, a coin cell battery CR2032 $(3 \mathrm{v} / 220 \mathrm{mAh})$ was chosen as the supply voltage to maintain the small size of the system.

The average current consumption for each slave node related to these parameters was approximately $170 \mu \mathrm{A}$ and the battery life was 255 days for training five hours a day (daily training requirements for cyclists) [88], while the average current consumption for the master node was $443 \mu \mathrm{A}$ and the battery life was 98 days.

Second Case. In typical practical use of a WSN application, the measured parameters do not change as rapidly as in cycling monitoring, and updating of the data every few seconds is acceptable. Therefore, a message rate of every 2 seconds $(0.5 \mathrm{~Hz})$ is adequate. In that case, the average current consumption of each slave node becomes $24 \mu \mathrm{A}$ which could extend the battery life to 1,698 days (4.5 years) for five hour training per day, whereas the average current consumption for the master is was $58 \mu \mathrm{A}$, which could extend battery life to 734 days ( 2 years). It is clear that the second case is an appropriate choice in a BWSM network. Figure 6 shows a chart of two cases of average current consumption and battery life for master and slave nodes.

The energy efficient was achieved in proposed BWSM by $88 \%$ and $95 \%$ for master node and slave node, respectively, compared with similar wireless standard technology (i.e., ANT) adopted in research work in [67], as shown in Figure 7.

\section{Future Work and Maturity Evaluation}

To assess the current level of maturity for research into cycling monitoring systems, a set of important features was introduced which best describe the functionality and properties of bicycle monitoring systems. The feasible scope of research that cycling sport monitoring incorporates will greatly benefit from the ability to gather data unobtrusively, without impeding motion or performance. These data contain information about the biomechanical and physiological

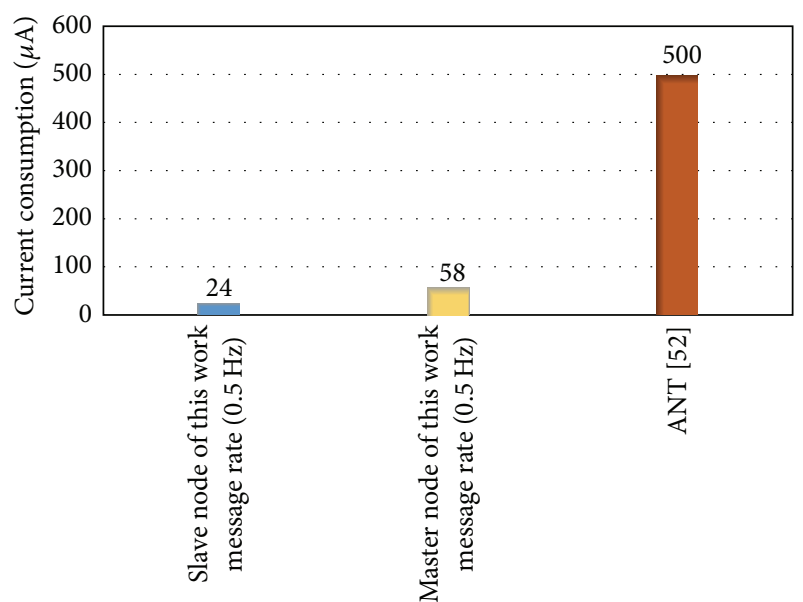

FIGURE 7: Current consumption comparison between proposed BWSM and research work [67] based on ANT.

parameters of the bicycle and cyclist, respectively, in addition to other parameters such as position and altitude.

New wireless radio communication technologies could simplify this data collection by allowing data to be gathered synchronously from various locations on the bicycle and cyclist. This would enable data from several sensors to be streamlined using data fusibility to allow further analysis. These data can be displayed in a clear and flexible manner for both the cyclist and trainer. ZigBee and Bluetooth are both common wireless radio communication interfaces that allow the establishment of WSNs for the collection of data from the nodes. In practice, newer products use Bluetooth and ZigBee when their main application is sensor networks and they are far more common in the world of WSNs.

Bluetooth low energy (BLE) also called smart Bluetooth is extension of Bluetooth version 4.0 [89].

It was released in October 2006, uses the same frequency ISM band of classic Bluetooth $(2.4 \mathrm{GHz})$ with $1 \mathrm{Mbps}$ data rates in a 10 meter range $[31,38]$. BLE is considered as an attractive technology for wireless sensor network applications demanding high data rates, but short range [44]. BLE enjoys several advantages over classic Bluetooth, which areas follows: (i) it is designed to transmit data at very low latency 15 times more efficiently than classic Bluetooth, (ii) only three channels are used for advertising, whereas 32 channels for classic Bluetooth, making BLE over 17 times more efficient than classic Bluetooth, (iii) saving a large amounts of energy because the slave devices do not stay in listening mode when it does not have any data to transmit $[38,90]$, and (iv) the power consumption of BLE is about one-tenth that of classic Bluetooth, which enables to use coin cell battery to power devices for more than a year [91].

BLE and ANT are both ultralow-power wireless sensor transmissions, both consume $15 \mathrm{~mA}$ in transmission mode, have similar sleep/active power, ability to operate for years on a single coin cell battery, data rate of $1 \mathrm{Mbps}$, wireless protocols operating in the range $2.4 \mathrm{GHz}$ to $2.483 \mathrm{GHz}$, immunity to interference, and they are used in wireless personal area network (WPAN). On the contrary, they have differences in 
TABLE 4: Dissimilarity in terms of technical specifications between BLE and ANT.

\begin{tabular}{lcc}
\hline Specifications & BLE & ANT \\
\hline Data channel & 40 & 125 \\
Transmission range & $10 \mathrm{~m}$ & $30 \mathrm{~m}$ \\
Latency & $6 \mathrm{~ms}$ & $\approx \mathrm{Zero}$ \\
Output power & $(-20-+10) \mathrm{dBm}$ & $0 /-6 /-12 /-18 \mathrm{dBm}$ \\
Payload size byte & $8-47$ & $1-32$ \\
Number of nodes in the network & Limited by the application & $2^{32}$ \\
Network standard & IEEE 802.15 .1 & Proprietary \\
Network topology & Simple star topology & Complex topologies \\
\hline
\end{tabular}

terms of specifications, as listed in Table 4 [44, 89-99]. On the other hand, the ANT is characterized by frequency agility, which is similar to frequency hopping schemes in Bluetooth technology. This property allows the ANT channel to change its operating frequency to improve coexistence with other wireless technology such as Bluetooth, Zigbee, and Wi-Fi. The ANT operating frequency automatically changes when significant degradation is observed in the channel [84, 100]. Furthermore, ANT requires less overhead to transmit the same amount of data, has more efficient scanning/initiating, and requires less transaction time per connections event. The BLE technology is still unproven, although many companies have declared their support of this technology [94], whereas the ANT is a proven technology with over 60 million devices in the market today [18].

This allows devices based on ANT are more efficient than BLE and they are preferred from different manufacturers to exchange data between ANT devices in several applications like health, sport, and fitness.

The ANT protocol has already been used in bicycle monitoring as in commercial products and has as-yet untapped potential in research. This type of wireless technology takes advantage of the cyclist's full capability and will move monitoring research into a new concept of WSNs as it has better features, such as ultra-low power consumption (a small coin-cell battery that lasts for $3+$ years), low complexity, zero latency, can support large number of devices on the network, and compatible with different types of network topologies. Unfortunately, it currently has a short communication distance of approximately $30 \mathrm{~m}$. Further hardware deployment using ANT for a bicycle monitoring system should be considered based on maturity evaluation.

\section{Concluding Remarks}

This study provided a survey of wireless sensor measurement systems for cycling based on three common wireless communication protocol standards (Bluetooth, ZigBee, and ANT) which are available commercially and academically. An assessment of the characteristics and behavior was introduced in terms of various performance metrics, including the data rate, output power, transmission range, power consumption, latency, complexity, network topology, and the number of devices in the network. A comparison of these wireless standard technologies was carried out to determine the most suitable for bicycle monitoring.

The results of the study point to ANT, which is a new wireless technology suitable for WSN in bicycle wireless monitoring. An example of this technology was adopted by the BWSM network; through this example, the power consumption was reduced compared to the similar ANT protocol in the medical rehabilitation application and the battery life was prolonged. Reducing power consumption and prolonging battery life were achieved by adjusting the message rate of ANT slave and master nodes and select the most suitable ANT chip that consumes less power (i.e., nRF24AP2$8 \mathrm{CH})$. This led to an energy efficient in proposed BWSM by $88 \%$ and $95 \%$ for master and slave nodes respectively.

The major advantages of ANT are ultralow-power consumption, low latency, and high reliability. It may also be used in other applications that require longer battery life for continuous monitoring, such as a monitoring system of older adults [101], coal mine safety monitoring system [102], and plant disease remote monitoring [103] in medical, industrial, and agricultural applications respectively.

\section{Conflict of Interests}

The authors declare that there is no conflict of interests regarding the publication of this paper.

\section{Acknowledgment}

This work was supported by Malaysia's Ministry of Higher Education-Universiti Kebangsaan Malaysia (UKM) under Grant ref. no: PKT1/2013.

\section{References}

[1] C. Young, P. R. Fleming, S. Dixon, and M. J. Carré, "Shoe signature monitoring for advanced running technique," in The Engineering of Sport 7, M. Estivalet and P. Brisson, Eds., vol. 2, pp. 35-43, Springer, Paris, France, 2008.

[2] K. Malhi, S. C. Mukhopadhyay, J. Schnepper, M. Haefke, and H. Ewald, "A zigbee-based wearable physiological parameters monitoring system," IEEE Sensors Journal, vol. 12, no. 3, pp. 423430, 2012.

[3] Y. Zhang and H. Xiao, "Bluetooth-based sensor networks for remotely monitoring the physiological signals of a patient," 
IEEE Transactions on Information Technology in Biomedicine, vol. 13, no. 6, pp. 1040-1048, 2009.

[4] E. Nemati, M. J. Deen, and T. Mondal, "A wireless wearable ECG sensor for long-term applications," IEEE Communications Magazine, vol. 50, no. 1, pp. 36-43, 2012.

[5] W. Zhang, P. Passow, E. Jovanov, R. Stoll, and K. Thurow, "A secure and scalable telemonitoring system using ultra-lowenergy wireless sensor interface for long-term monitoring in life science applications," in Proceedings of the IEEE International Conference on Automation Science and Engineering (CASE '13), pp. 617-622, Madison, Wis, USA, August 2013.

[6] S. Armstrong, "Wireless connectivity for health and sports monitoring: a review," British Journal of Sports Medicine, vol. 41, no. 5, pp. 285-289, 2007.

[7] A. H. Omre and S. Keeping, "Bluetooth low energy: wireless connectivity for medical monitoring," Journal of Diabetes Science and Technology, vol. 4, no. 2, pp. 457-463, 2010.

[8] R. Tesoriero, J. A. Gallud, M. D. Lozano, and V. M. R. Penichet, "Tracking autonomous entities using RFID technology," IEEE Transactions on Consumer Electronics, vol. 55, no. 2, pp. 650655, 2009.

[9] A. Honkasuo, A. Hamalainen, P. Jappinen, J. Jaaskelainen, and J. Porras, "Mobile bicycle monitoring system," in Proceeding of the 7th IEEE Workshop on Mobile Computing Systems and Applications (WMCSA '06), p. 44, Orcas, Wash, USA, August 2005.

[10] N. Baker, "ZigBee and Bluetooth strengths and weaknesses for industrial applications," IEE Computing and Control Engineering, vol. 16, no. 2, pp. 20-25, 2005.

[11] W. Guo, W. M. Healy, and M. Zhou, "Battery discharge characteristics of wireless sensors in building applications," in Proceedings of the 9th IEEE International Conference on Networking, Sensing and Control (ICNSC '12), pp. 133-138, Beijing, China, April 2012.

[12] A. Kailas, V. Cecchi, and A. Mukherjee, "A survey of communications and networking technologies for energy management in buildings and home automation," Journal of Computer Networks and Communications, vol. 2012, Article ID 932181, 12 pages, 2012.

[13] S.-K. Chen, T. Kao, C.-T. Chan et al., "A reliable transmission protocol for zigbee-based wireless patient monitoring," IEEE Transactions on Information Technology in Biomedicine, vol. 16, no. 1, pp. 6-16, 2012.

[14] A. Betzler, C. Gomez, I. Demirkol, and J. Paradells, "A holistic approach to ZigBee performance enhancement for home automation networks," Sensors, vol. 14, pp. 14932-14970, 2014.

[15] K.-Y. Lian, S.-J. Hsiao, and W.-T. Sung, "Mobile monitoring and embedded control system for factory environment," Sensors, vol. 13, no. 12, pp. 17379-17413, 2013.

[16] P. Christ, B. Neuwinger, F. Werner, and U. Rückert, "Performance analysis of the nRF24L01 ultra-low-power transceiver in a multi-transmitter and multi-receiver scenario," in Proceedings of the IEEE Sensors, pp. 1205-1208, October 2011.

[17] P. Smith, "Comparisons between low power wireless technologies," US Patent CS-213199-AN, 2011.

[18] ANT Wireless, 2014, http://www.thisisant.com/.

[19] S. Sharma, A. L. Vyas, B. Thakker, D. Mulvaney, and S. Datta, "Wireless body area network for health monitoring," in Proceedings of the 4th International Conference on Biomedical Engineering and Informatics (BMEI '11), pp. 2183-2186, IEEE, Shanghai, China, October 2011.
[20] G. Hong and S. Jianxiu, "Design of the temperature signal wireless receiver and display system on polishing interface in chemical mechanical polishing," Procedia Engineering, vol. 24, pp. 417-421, 2011.

[21] M. A. A. Hassan, "A review of wireless technology usage for mobile robot controller," in Proceeding of the International Conference on System Engineering and Modeling (ICSEM '12), pp. 7-12, Singapore, June 2012.

[22] S. Khssibi, H. Idoudi, A. van den Bossche, T. Val, and L. A. Saidane, "Presentation and analysis of a new technology for lowpower wireless sensor network," International Journal of Digital Information and Wireless Communications, vol. 3, no. 1, pp. 7586, 2013.

[23] J.-S. Lee, Y.-W. Su, and C.-C. Shen, "A comparative study of wireless protocols: bluetooth, UWB, ZigBee, and Wi-Fi," in Proceedings of the 33rd Annual Conference of the IEEE Industrial Electronics Society (IECON '07), pp. 46-51, Taipei, Taiwan, November 2007.

[24] M. Li and M. Zhuang, "An overview of Physical layers on wireless body area network," in Proceedings of the International Conference on Anti-Counterfeiting, Security and Identification (ASID '12), pp. 1-5, Taipei, Taiwan, August 2012.

[25] M.-S. Pan and Y.-C. Tseng, ZigBee Wireless Sensor Networks and Their Applications, National Chiao Tung University, Hsin-Chu, Hsinchu, Taiwan, 2006.

[26] A. Pantelopoulos and N. G. Bourbakis, "A survey on wearable sensor-based systems for health monitoring and prognosis," IEEE Transactions on Systems, Man and Cybernetics. Part C: Applications and Reviews, vol. 40, no. 1, pp. 1-12, 2010.

[27] L. Ruiz-Garcia, L. Lunadei, P. Barreiro, and J. I. Robla, "A review of wireless sensor technologies and applications in agriculture and food industry: state of the art and current trends," Sensors, vol. 9, no. 6, pp. 4728-4750, 2009.

[28] "nRF24AP2 ultra-low power transceiver with ANT ultralow power network protocol technical backgrounder," 2010, http://www.nordicsemi.com/.

[29] T. Vuorela, V.-P. Seppä, J. Vanhala, and J. Hyttinen, "Wireless measurement system for bioimpedance and ECG," in Proceedings of the 13th International Conference on Electrical Bioimpedance and the 8th Conference on Electrical Impedance Tomography (ICEBI '07), vol. 17, pp. 248-251, Graz, Austria, September 2007.

[30] Z. Yiming, Y. Xianglong, G. Xishan, Z. Mingang, and W. Liren, "A design of greenhouse monitoring \& control system based on ZigBee wireless sensor network," in Proceedings of the International Conference on Wireless Communications, Networking and Mobile Computing (WiCOM '07), pp. 2563-2567, Shanghai, China, September 2007.

[31] T. Rault, A. Bouabdallah, and Y. Challal, "Energy efficiency in wireless sensor networks: a top-down survey," Computer Networks, vol. 67, pp. 104-122, 2014.

[32] F. Casamassima, E. Farella, and L. Benini, "Power saving policies for multipurpose WBAN," in Proceedings of the 23rd International Workshop on Power and Timing Modeling, Optimization and Simulation (PATMOS '13), pp. 83-90, Karlsruhe, Germany, September 2013.

[33] D. M. Amzucu, H. Li, and E. Fledderus, "Indoor radio propagation and interference in $2.4 \mathrm{GHz}$ wireless sensor networks: measurements and analysis," Wireless Personal Communications, vol. 76, no. 2, pp. 245-269, 2014.

[34] ZigBee Wireless Interfaces and Modules, 2013, http://www.kanda .com/zigbee-wireless.html. 
[35] J. Wang, "Zigbee light link and its applicationss," IEEE Wireless Communications, vol. 20, no. 4, pp. 6-7, 2013.

[36] A. Z. Abbasi, N. Islam, and Z. A. Shaikh, "A review of wireless sensors and networks' applications in agriculture," Computer Standards and Interfaces, vol. 36, no. 2, pp. 263-270, 2014.

[37] M. Kohvakka, J. Suhonen, M. Kuorilehto, V. Kaseva, M. Hännikäinen, and T. D. Hämäläinen, "Energy-efficient neighbor discovery protocol for mobile wireless sensor networks," Ad Hoc Networks, vol. 7, no. 1, pp. 24-41, 2009.

[38] C. Buratti, A. Conti, D. Dardari, and R. Verdone, "An overview on wireless sensor networks technology and evolution," Sensors, vol. 9, no. 9, pp. 6869-6896, 2009.

[39] R. Tabish, A. Ben Mnaouer, F. Touati, and A. M. Ghaleb, "A comparative analysis of BLE and 6LoWPAN for U-HealthCare applications," in Proceedings of the 7th IEEE GCC Conference and Exhibition (GCC '13), pp. 286-291, Doha, Qatar, November 2013.

[40] R. Nagarajan and R. Dhanasekaran, "Implementation of wireless data transmission in monitoring and control," in Proceedings of the 2nd International Conference on Communication and Signal Processing (ICCSP '13), pp. 83-87, Melmaruvathur, India, April 2013.

[41] N. Langhammer and R. Kays, "Enhanced frequency hopping for reliable interconnection of low power smart home devices," in Proceedings of the 8th IEEE International Wireless Communications and Mobile Computing Conference (IWCMC '12), pp. 305310, Limassol, Cyprus, August 2012.

[42] S. Gasparrini, E. Gambi, and S. Spinsante, "Evaluation and possible improvements of the ANT protocol for home heart monitoring applications," in Proceedings of the 2nd IEEE International Workshop on Measurements and Networking ( $M$ and $N$ '13), pp. 214-219, Naples, Italy, October 2013.

[43] Digital sensing technology for wireless sport, fitness and health monitoring, 2013, http://www.dynastream.com/.

[44] P. Rawat, K. D. Singh, H. Chaouchi, and J. M. Bonnin, "Wireless sensor networks: a survey on recent developments and potential synergies," The Journal of Supercomputing, vol. 68, no. 1, pp. 148, 2014.

[45] T. Kuhn, T. Jaitner, and R. Gotzhein, "Online-monitoring of multiple track cyclists during training and competition," in The Engineering of Sport 7, M. Estivalet and P. Brisson, Eds., vol. 1, pp. 405-412, Springer, Paris, France, 2008.

[46] A. Le, L. Litz, and T. Jaitner, "A model predictive controller for sensor-based training optimization of a cyclist group," in The Engineering of Sport 7, M. Estivalet and P. Brisson, Eds., vol. 1, pp. 413-424, Springer, Paris, France, 2008.

[47] A. Le, T. Jaitner, and L. Litz, "Sensor-based training optimization of a cyclist group," in Proceedings of the 7th International Conference on Hybrid Intelligent Systems (HIS '07), pp. 265-270, Kaiserlautern, Germany, September 2007.

[48] J. Chen, B. Kuo, and C. Chiang, "The development of wireless electrocardiography for bicycling and stairs-climbing," Journal of Biomechanics, vol. 40, p. S663, 2007.

[49] A. Zhan, M. Chang, Y. Chen, and A. Terzis, "Accurate caloric expenditure of bicyclists using cellphones," in Proceedings of the 10th ACM Conference on Embedded Networked Sensor Systems (SenSys '12), pp. 71-84, Toronto, Canada, November 2012.

[50] R. B. Edmund, High-Tech Cycling, Human Kinetics, Champaign, Ill, USA, 2nd edition, 2003.

[51] A. S. Gardner, J. C. Martin, D. T. Martin, M. Barras, and D. G. Jenkins, "Maximal torque- and power-pedaling rate relationships for elite sprint cyclists in laboratory and field tests," European Journal of Applied Physiology, vol. 101, no. 3, pp. 287292, 2007.

[52] W. Bertucci, R. Taiar, Y. Toshev, and T. Letellier, "Comparison of biomechanical criteria in cycling maximal effort test," International Journal of Sports Science and Engineering, vol. 2, no. 1, pp. 36-46, 2008.

[53] A. C. Lim, E. P. Homestead, A. G. Edwards, T. C. Carver, R. Kram, and W. C. Byrnes, "Measuring changes in aerodynamic/rolling resistances by cycle-mounted power meters," Medicine and Science in Sports and Exercise, vol. 43, no. 5, pp. 853-860, 2011.

[54] J. Lieh, "Determination of cycling speed using a closed-form solution from nonlinear dynamic equations," Human Power eJournal, vol. 10, no. 3, pp. 1-9, 2006.

[55] T. Dahmen and D. Saupe, "Calibration of a power-speed-model for road cycling using real power and height data," International Journal of Computer Science in Sport, vol. 10, pp. 18-36, 2011.

[56] A. B. Dahlin, "Size matters: problems and advantages associated with highly miniaturized sensors," Sensors, vol. 12, no. 3, pp. 3018-3036, 2012.

[57] S. Park and S. Jayaraman, "Smart textile-based wearable biomedical systems: a transition plan for research to reality," IEEE Transactions on Information Technology in Biomedicine, vol. 14, no. 1, pp. 86-92, 2010.

[58] D. Teichmann, A. Kuhn, S. Leonhardt, and M. Walter, "The main shirt: a textile-integrated magnetic induction sensor array," Sensors, vol. 14, no. 1, pp. 1039-1056, 2014.

[59] W. Walker, A. L. P. Aroul, and D. Bhatia, "Mobile health monitoring systems," in Proceedings of the 31st Annual International Conference of the IEEE Engineering in Medicine and Biology Society (EMBC '09), pp. 5199-5202, September 2009.

[60] D. L. Peterson, J. K. Moore, D. Fintelman, and M. Hubbard, "Low-power, modular, wireless dynamic measurement of bicycle motion," Procedia Engineering, vol. 2, no. 2, pp. 2949-2954, 2010.

[61] H. Hayashi, O. Kagami, and M. Harada, "Results of field trials with wide-area ubiquitous network," in Proceedings of the IEEE MTT-S International Microwave Symposium Digest (IMS '12), pp. 1-3, Montreal, Canada, June 2012.

[62] M. Olieman, R. Marin-Perianu, and M. Marin-Perianu, "Measurement of dynamic comfort in cycling using wireless acceleration sensors," Procedia Engineering, vol. 34, pp. 568-573, 2012.

[63] R. Marin-Perianu, M. Marin-Perianu, P. Havinga et al., "A performance analysis of a wireless body-area network monitoring system for professional cycling," Personal and Ubiquitous Computing, vol. 17, no. 1, pp. 197-209, 2013.

[64] C.-M. Yang, C.-C. Wu, C.-M. Chou, and C.-W. Yang, “Textilebased monitoring system for biker," in Proceeding of the 9th IEEE International Conference on Information Technology and Applications in Biomedicine (ITAB '09), pp. 1-4, November 2009.

[65] F. Casamassima, A. Ferrari, B. Milosevic, P. Ginis, E. Farella, and L. Rocchi, "A wearable system for gait training in subjects with Parkinson's disease," Sensors, vol. 14, no. 4, pp. 6229-6246, 2014.

[66] A. Baca, P. Kornfeind, E. Preuschl, S. Bichler, M. Tampier, and H. Novatchkov, "A server-based mobile coaching system," Sensors, vol. 10, no. 12, pp. 10640-10662, 2010.

[67] A. Johansson, W. Shen, and Y. Xu, "An ANT based wireless body sensor biofeedback network for medical E-health care," in Proceedings of the 7th International Conference on Wireless Communications, Networking and Mobile Computing (WiCOM '11), pp. 1-5, September 2011. 
[68] K.-M. Yu, J. Zhou, C.-Y. Yu et al., "An event-based wireless navigation and healthcare system for group recreational cycling," in Proceedings of the 5th International Conference on Mobile Adhoc and Sensor Networks (MSN '09), pp. 294-298, Fujian, China, December 2009.

[69] C. Raut and V. Giripunje, “The real-time monitoring system for in-patient based on biomedical data acquisition system," in Proceedings of the International Conference on Information and Network Technology (ICINT '11), pp. 110-114, Singapore, 2011.

[70] D. K. Patil and R. Shastri, "Design of wireless electronic stethoscope based on zigbee," International Journal of Distributed and Parallel Systems, vol. 3, no. 1, pp. 351-359, 2012.

[71] B. Subramanian and A. Ramasamy, "Efficient zigbee based health care system for arrhythmia detection in electrocardiogram," European Journal of Scientific Research, vol. 69, no. 2, pp. 180-187, 2012.

[72] A. Sagahyroon, F. Aloul, A. R. Al-Ali, M. S. Bahrololoum, F. Makhsoos, and N. Hussein, "Monitoring patients' signs wirelessly," in Proceedings of the 1st Middle East Conference on Biomedical Engineering (MECBME '11), pp. 283-286, Sharjah, UAE, February 2011.

[73] S. C. Mukhopadhyay, A. Gaddam, and G. S. Gupta, "Wireless sensors for home monitoring-a review," Recent Patents on Electrical Engineering, vol. 1, pp. 32-39, 2008.

[74] N. Belgacem and F. Bereksi-Reguig, "Bluetooth portable device for ECG and patient motion monitoring," Nature and Technology, vol. 4, pp. 19-23, 2011.

[75] N. Belgacem, S. Assous, and F. Bereksi-Reguig, "Bluetooth portable device and Matlab-based GUI for ECG signal acquisition and analisys," in Proceedings of the 7th International Workshop on Systems, Signal Processing and their Applications (WOSSPA '11), pp. 87-90, Tipaza, Algeria, May 2011.

[76] A. Tura, M. Badanai, D. Longo, and L. Quareni, "A medical wearable device with wireless bluetooth-based data transmission," Measurement Science Review, vol. 3, pp. 1-4, 2003.

[77] V. T. Bai and S. Srivatsa, "Design and simulation of portable telemedicine system for high risk cardiac patients," International Journal of Biomedical Science, vol. 1, pp. 219-223, 2006.

[78] Y. V. Varshney and A. K. Sharma, "Design \& simulation of Zigbee transceiver system using Matlab," International Journal of Engineering Trends and Technology, vol. 4, pp. 1316-1319, 2013.

[79] E. D. Zubiete, L. F. Luque, A. Rodriguez, and I. G. González, "Review of wireless sensors networks in health applications," in Proceedings of the Annual International Conference of the IEEE Engineering in Medicine and Biology Society (EMBC '11), pp. 1789-1793, Boston, Mass, USA, August-September 2011.

[80] SRM, 2013, http://www.srm.de.

[81] Cycleops Power Meters, 2013, http://www.powertap.com/.

[82] Garmin Vector, 2013, http://sites.garmin.com/vector/\#suite.

[83] Pioneer, 2013, http://www.pioneerelectronics.com/.

[84] ANT Message Protocol and Usage, 2014, http://www.thisisant .com/.

[85] “Power Estimator," 2013, http://www.thisisant.com/developer/ components/power-estimator.

[86] Ultra low power wireless solutions, 2013, http://www.nordicsemi.com/eng/Products/ANT/nRF24AP2-8CH.

[87] ANT Burst Transfers, 2014, http://www.thisisant.com.

[88] J. Beer, "A special report from peak performance/training for cyclists/the road to success-training secrets of the pros," 2006, http://www.worldclassbodybuilding.com/.
[89] N. Langhammer and R. Kays, "Performance evaluation of wireless home automation networks in indoor scenarios," IEEE Transactions on Smart Grid, vol. 3, no. 4, pp. 2252-2261, 2012.

[90] C. Gomez, J. Oller, and J. Paradells, "Overview and evaluation of bluetooth low energy: an emerging low-power wireless technology," Sensors, vol. 12, no. 9, pp. 11734-11753, 2012.

[91] M. McGrath and C. Scanaill, "Wellness, fitness, and lifestyle sensing applications," in Sensor Technologies, pp. 217-248, Apress, 2013.

[92] I. Caballero, J. Vicente Sáez, and B. García Zapirain, "Review and new proposals for zigbee applications in healthcare and home automation," in Ambient Assisted Living, J. Bravo, R. Hervás, and V. Villarreal, Eds., vol. 6693, pp. 101-108, Springer, Berlin, Germany, 2011.

[93] H. Joh and I. Ryoo, "A hybrid Wi-Fi P2P with bluetooth low energy for optimizing smart device's communication property," Peer-to-Peer Networking and Applications, 2014.

[94] J. Wen and J. Nelson, "Modelling and performance analysis of an adaptive state-transition approach for power saving in Bluetooth," Simulation Modelling Practice and Theory, vol. 31, pp. 77-95, 2013.

[95] E. Mackensen, M. Lai, and T. M. Wendt, "Performance analysis of an Bluetooth Low Energy sensor system," in Proceeding of the 1st IEEE International Symposium on Wireless Systems (IDAACS-SWS '12), pp. 62-66, Offenburg, Germany, September 2012.

[96] J. Haase, "Wireless network standards for building automation," in Embedded Systems for Smart Appliances and Energy Management, C. Grimm, P. Neumann, and S. Mahlknecht, Eds., vol. 3, pp. 53-65, Springer, New York, NY, USA, 2013.

[97] K. Mikhaylov, N. Plevritakis, and J. Tervonen, "Performance analysis and comparison of bluetooth low energy with IEEE 802.15. 4 and SimpliciTI," Journal of Sensor and Actuator Networks, vol. 2, pp. 589-613, 2013.

[98] M. Zareei, A. Zarei, R. Budiarto, and M. A. Omar, "A comparative study of short range wireless sensor network on high density networks," in Proceedings of the 17th Asia Pacific Conference on Communications (APCC '11), pp. 247-252, Sabah, Malaysia, October 2011.

[99] S. Adibi, "Link technologies and BlackBerry mobile Health (mHealth) solutions: a review," IEEE Transactions on Information Technology in Biomedicine, vol. 16, no. 4, pp. 586-597, 2012.

[100] A. H. Omre, "Reducing healthcare costs with wireless technology," in Proceeding of the 6th International Workshop on Wearable and Implantable Body Sensor Networks (BSN '09), pp. 65-70, Berkeley, Calif, USA, June 2009.

[101] R. Belchior, D. Júnior, and A. Monteiro, "ANT+ medical health kit for older adults," in Wireless Mobile Communication and Healthcare, B. Godara and K. Nikita, Eds., vol. 61 of Lecture Notes of the Institute for Computer Sciences, pp. 20-29, Springer, Berlin, Germany, 2013.

[102] J. Song, Y. Zhu, and F. Dong, "Automatic monitoring system for coal mine safety based on wireless sensor network," in Proceedings of the Cross Strait Quad-Regional Radio Science and Wireless Technology Conference (CSQRWC '11), pp. 933-936, Harbin, China, July 2011.

[103] C. Zhang, X. Wang, and X. Li, "Design of monitoring and control plant disease system based on DSP\&FPGA," in Proceedings of the 2nd International Conference on Networks Security, Wireless Communications and Trusted Computing (NSWCTC '10), pp. 479-482, Wuhan, China, April 2010. 
[104] A. C. Wong, M. Dawkins, G. Devita et al., "A 1 v 5 mA multimode IEEE 802.15.6/bluetooth low-energy WBAN transceiver for biotelemetry applications," IEEE Journal of Solid-State Circuits, vol. 48, no. 1, pp. 186-198, 2013.

[105] E. Georgakakis, S. Nikolidakis, D. Vergados, and C. Douligeris, "An analysis of bluetooth, Zigbee and bluetooth low energy and their use in WBANs," in Wireless Mobile Communication and Healthcare, J. Lin and K. Nikita, Eds., vol. 55, pp. 168-175, Springer, Berlin, Germany, 2011.

[106] J. Decuir, "Introducing bluetooth smart: part II: applications and updates," IEEE Consumer Electronics Magazine, vol. 3, pp. 25-29, 2014.

[107] R. Cavallari, F. Martelli, R. Rosini, C. Buratti, and R. Verdone, "A survey on wireless body area networks: technologies and design challenges," IEEE Communications Surveys and Tutorials, vol. 16, no. 3, pp. 1635-1657, 2014.

[108] J. Liu, G. Sun, D. Zhao, X. Yao, and Y. Zhang, "MCU-controlling based bluetooth data transferring system," Procedia Engineering, vol. 29, pp. 2109-2115, 2012.

[109] J. Padgette, K. Scarfone, and L. Chen, "Guide to bluetooth security," NIST Special Publication, vol. 800, p. 121, 2012.

[110] L. Mraz, V. Cervenka, D. Komosny, and M. Simek, "Comprehensive performance analysis of zigbee technology based on real measurements," Wireless Personal Communications, vol. 71, no. 4, pp. 2783-2803, 2013.

[111] V. Custodio, F. J. Herrera, G. López, and J. I. Moreno, "A review on architectures and communications technologies for wearable health-monitoring systems," Sensors, vol. 12, no. 10, pp. 1390713946, 2012.

[112] G. C. May, A. R. Doherty, A. F. Smeaton, and D. G. Warrington, "Correlating multimodal physical sensor information with biological analysis in ultra endurance cycling," Sensors, vol. 10, no. 8, pp. 7216-7235, 2010.

[113] T. Reinhardt, W. Norbert, J. Thomas, and V. Roland, "Power measurement in cycling using inductile coupling of energy and data," in The Engineering of Sport 7, M. Estivalet and P. Brisson, Eds., vol. 1, pp. 397-403, Springer, Paris, France, 2008.

[114] P. Barratt, "SRM Torque Analysis of Standing Starts in Track Cycling," in The Engineering of Sport 7, M. Estivalet and P. Brisson, Eds., vol. 1, pp. 443-448, Springer, Paris, France, 2008.

[115] R. R. Bini, P. A. Hume, and A. Cerviri, "A comparison of cycling SRM crank and strain gauge instrumented pedal measures of peak torque, crank angle at peak torque and power output," Procedia Engineering, vol. 13, pp. 56-61, 2011.

[116] S. J. Selvarani, "Online health monitoring system using Zigbee," International Journal on Computer Science and Engineering, vol. 3, pp. 1578-1583, 2011.

[117] E. Jovanov, A. Milenkovic, C. Otto, and P. C. de Groen, "A wireless body area network of intelligent motion sensors for computer assisted physical rehabilitation," Journal of NeuroEngineering and Rehabilitation, vol. 2, article 6, 2005.

[118] S. Hu, H. Wei, Y. Chen, and J. Tan, "A real-time cardiac arrhythmia classification system with wearable sensor networks," Sensors, vol. 12, no. 9, pp. 12844-12869, 2012.

[119] M. Tavakoli, L. Turicchia, and R. Sarpeshkar, "An ultra-lowpower pulse oximeter implemented with an energy-efficient transimpedance amplifier," IEEE Transactions on Biomedical Circuits and Systems, vol. 4, no. 1, pp. 27-38, 2010.

[120] R. Trobec, A. Rashkovska, and V. Avbelj, "Two proximal skin electrodes-a respiration rate body sensor," Sensors, vol. 12, no. 10, pp. 13813-13828, 2012.
[121] C. A. Boario, M. Lasagni, and K. Römer, "Non-invasive measurement of core body temperature in Marathon runners," in Proceedings of the IEEE International Conference on Body Sensor Networks (BSN '13), pp. 1-6, Cambridge, Mass, USA, May 2013.

[122] H.-Y. Shin, F.-L. Un, and K.-W. Huang, "A sensor-based tracking system for cyclist group," in Proceedings of the 7th International Conference on Complex, Intelligent, and Software Intensive Systems (CISIS '13), pp. 617-622, Taichung, Taiwan, July 2013.

[123] S. B. Eisenman, E. Miluzzo, N. D. Lane, R. A. Peterson, G.-S. Ahn, and A. T. Campbell, "BikeNet: a mobile sensing system for cyclist experience mapping," ACM Transactions on Sensor Networks, vol. 6, pp. 87-101, 2009.

[124] J. Y. Chen, F. Wen, C. H. Lin, and D.-F. Lin, "A new automatic measurement system for a bicycle," in Proceedings of the IEEE International Conference on Mechatronics (ICM '05), pp. 514519, July 2005. 

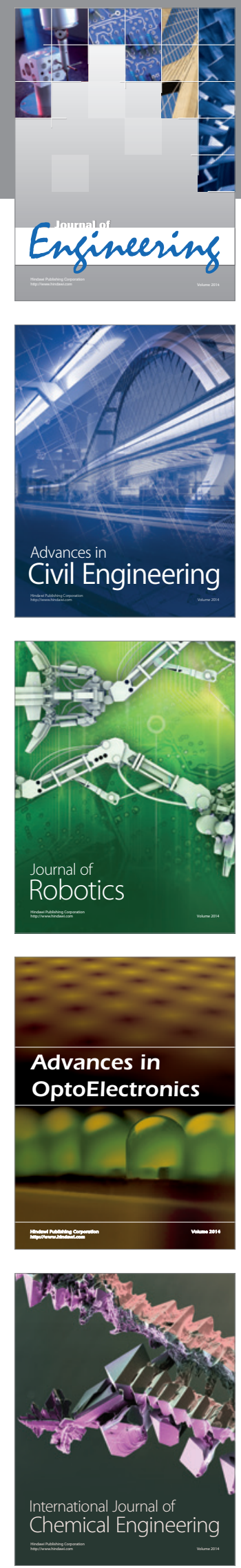

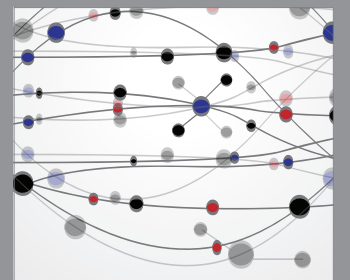

The Scientific World Journal
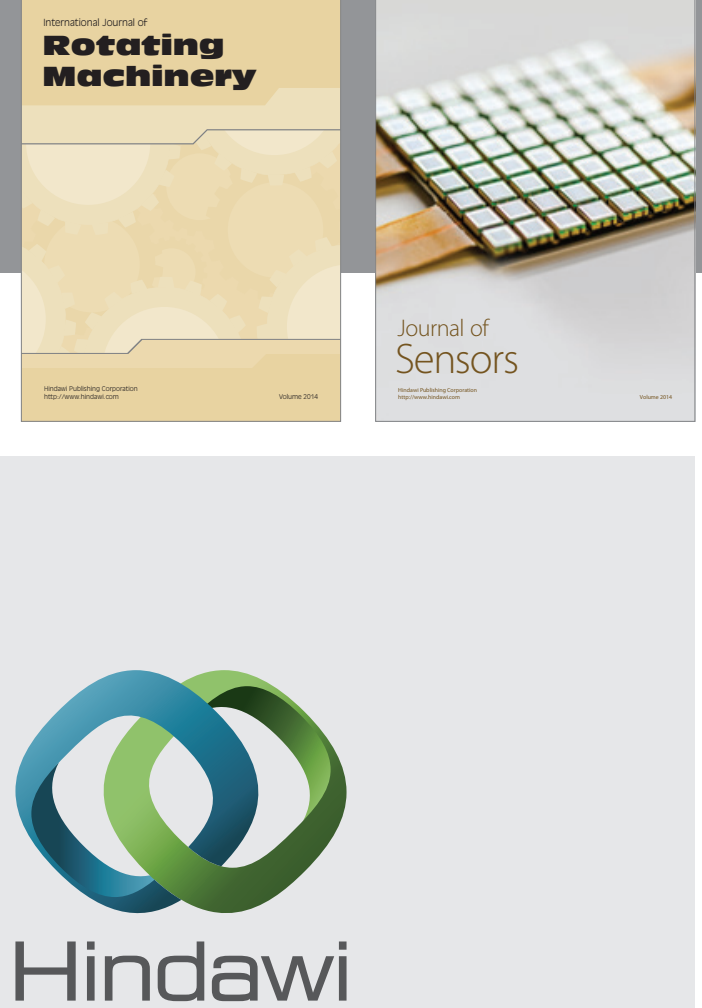

Submit your manuscripts at http://www.hindawi.com
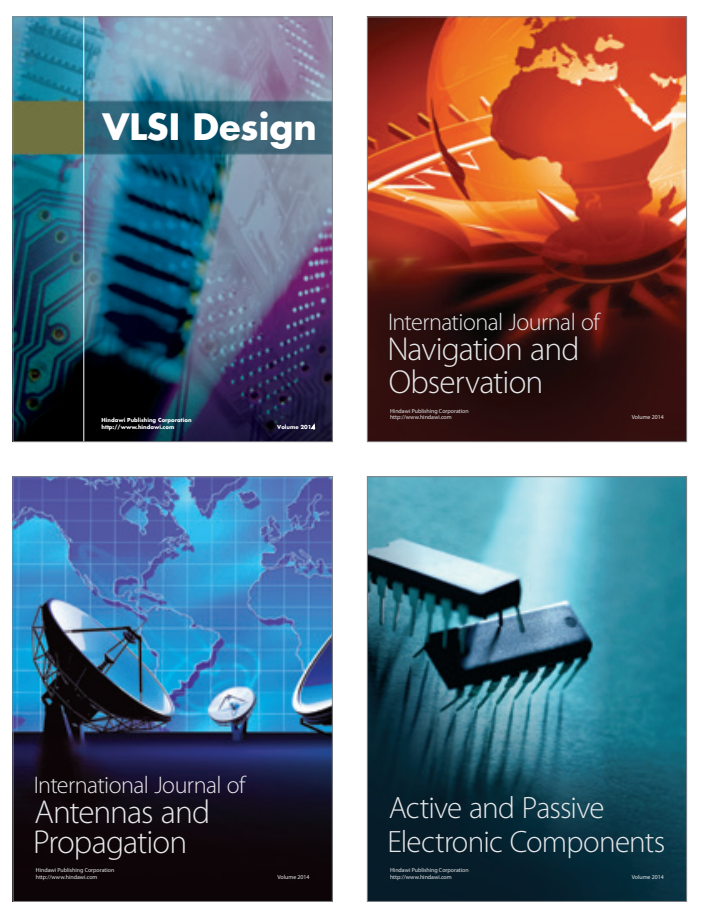
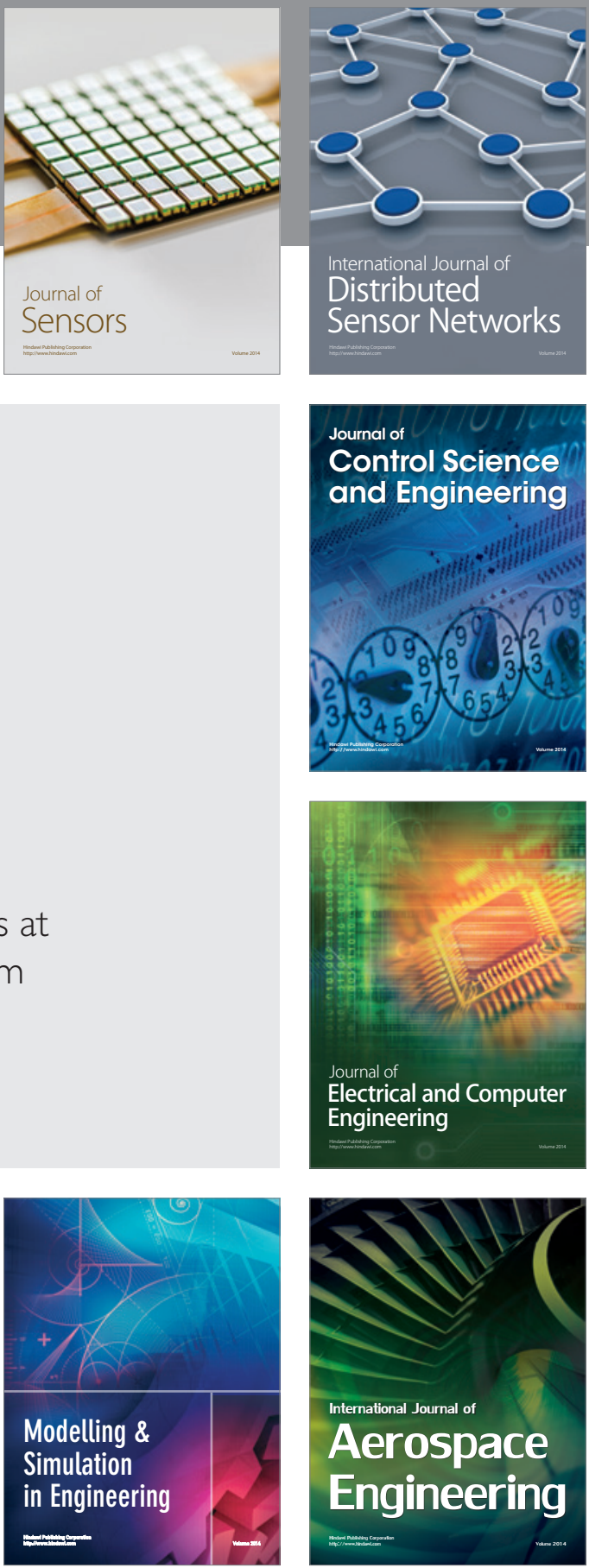

Journal of

Control Science

and Engineering
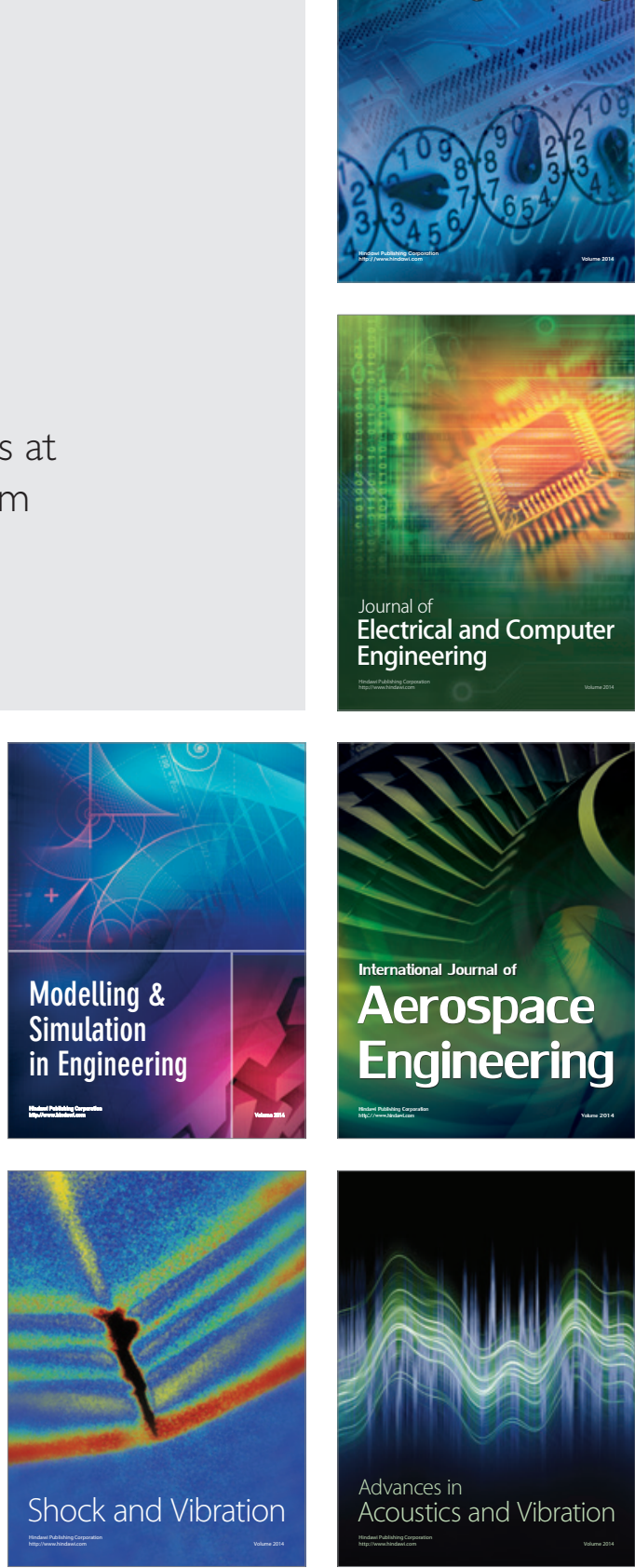